\title{
LEVANTAMENTO DE FUNGOS TERMÓFILOS ASSOCIADOS A PILHAS DE CAVACOS DE Eucalyptus spp.
}

\author{
CELSO GARCIA AUER
}

Orientador: Prof. Dr. TASSO LEO KRÜGNER

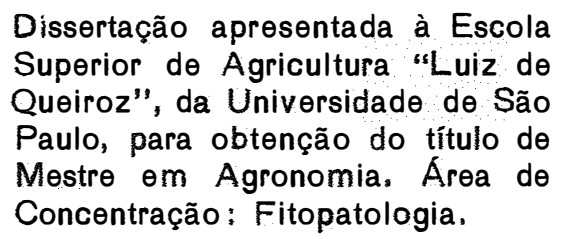

$P|R A C| C A B A$

Estado de São Paulo - Brasil Junho - 1986 
.iii.

A meus pais,

Dervita e Ernesto dedico.

A Deus, agradeço. 


\section{AGRADECIMENTOS}

Pelas inúmeras colaborações prestadas, difícil será relacionä-las, mas faz-se necessārio e mister reconhecer e agradecer:

Ao Professor Dr. Tasso Leo Krügner, pelos ensinamentos, experiên cia adquirida e orientação;

Ao Professor Dr. Luiz E.G. Barrichezzo, pelo apoio, ensinamen tos e orientação;

Aos Professores Dr. Hiroshi Kimati, Dr. Paulo de C.T. de CarvaTho, Dr. Clélio Lima Salgado, Dr. Eric Balmer, Dr. Armando Bergamin Filho, pelos ensinamentos;

Ao Instituto de Botânica - SP, na pessoa dos professores Dr. Adauto Ivo Milanez e Dra. Sandra F.B. Trufem, pelos ensinamen tos e orientação nos trabalhos de identificação dos fungos;

Aos Engo Ftal. Mestre Marcio Pinheiro Ferrari e Eng P Agro Mestre Wagner Bettiol, pela grande amizade, apoio, colaboração e sugestões; 
Aos acadêmicos Isabel Tsutsumi, pela colaboração nos ensaios e Luis Eduardo Aranha Camargo, pelas sugestões;

A Champion Papel e Celuzose $S / A$, na pessoa do Engọ Químico Elavio Tesser e ex-funcionário Engọ Ftal. Ricardo Ardente de Alme $\underline{i}$ da, pelo apoio e pelas facilidades para o desenvolvimento da pesquisa;

A Secretaria de Tecnologia Industrial - STI/MIC, pelo financiamento dos trabalhos de pesquisa;

A Fundasão de Amparo à Eesquisa do Estado de são Pauzo - FAPESP, pela bolsa de estudos fornecida;

A turma de alunos da pós-graduacão em Fitopatologia, que de uma maneira ou outra favoreceram o desempenho dos trabalhos científicos;

Aos funcionários dos Depto. de Fitopatologia e do Depto. de Ciéncias Florestais, pelo grande auxílio prestado. 
RESUMO $\ldots \ldots \ldots \ldots \ldots \ldots \ldots \ldots \ldots \ldots \ldots \ldots \ldots \ldots \ldots \ldots$

SUMMARY $\ldots \ldots \ldots \ldots \ldots \ldots \ldots \ldots \ldots \ldots \ldots \ldots \ldots \ldots \ldots \ldots \ldots \ldots \ldots \ldots \ldots$

I - INTRODUCGAO $\ldots \ldots \ldots \ldots \ldots \ldots \ldots \ldots \ldots \ldots \ldots \ldots \ldots \ldots$

I I - Revisáo de literatura $\ldots \ldots \ldots \ldots \ldots \ldots \ldots \ldots$

2.1. Armazenamento de madeira na forma de ca

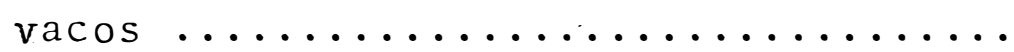

2.2. Caracteristicas gerais de microrganis mos termófilos .................. 06

2.3. Pilhas de cavacos com auto-aquecimento. 09

III - MATERIAL E METODOS ................. 16

3.1. Montagem, monitoramento da pilha e cole ta de cavacos de eucalipto .......... 16

3.2. Atividades conduzidas no laboratörio .. 24

3.2.1. ENSAIO 1 - Teste com diferentes meios de cultura pura para isola mento de microrganismos termófi-

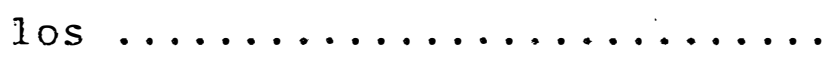

3.2.2. ENSAIO 2 - Comparação entre BDA e hidrolisado de madeira-ägar pa ra isolamento de fungos termófilos $\ldots \ldots \ldots \ldots \ldots \ldots \ldots \ldots \ldots \ldots \ldots$ 
3.2.3. Isolamento de fungos termófilos a partir dos cavacos coletados da

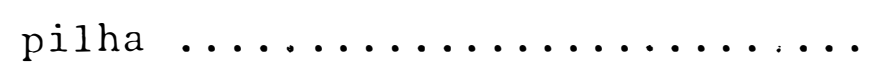

3.2.4. Isolamento de fungos termófilos em vârios locais próximos à fábrica de

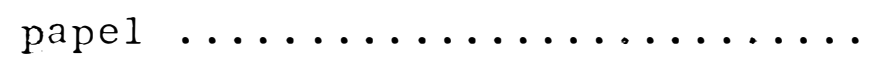

3.2.5. ENSAIO 3 - Determinação de taxas de crescimento micelial, dos fungos ter mofilos isolados, em diferentes tem

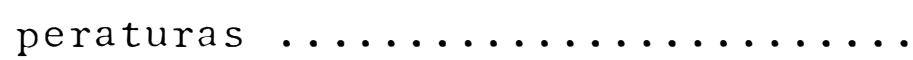

3.2.6. ENSAIO 4 - Avaliação da germinação dos esporos de fungos termófilos, em diferentes temperaturas ..........

3.2.7. ENSAIO 5 - Avaliação do efeito de diferentes fontes de carbono no desenvolvimento de três fungos termó-

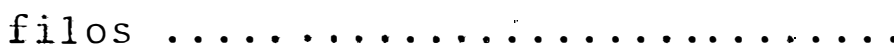

3.2.8. ENSAIO 6 - Teste de hidrolisado de madeira-âgar com meio de cultura pa ra fungos termófilos, isolados de

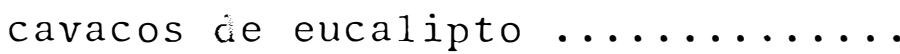

3.4. Identificação dos fungos termófilos isola- dos da pilha de cavacos de eucalipto com

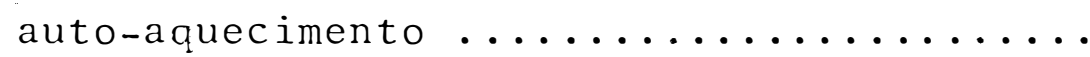

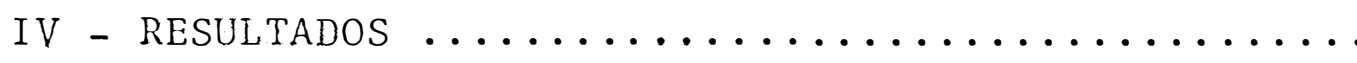

4.1. Monitoramento das condições da pilha com au

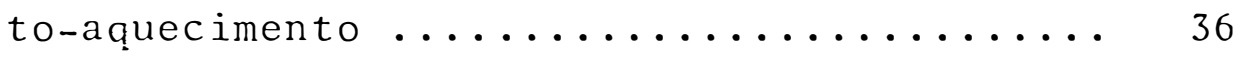

4.2. Atividades conduzidas no laboratório .......

4.2.1. Efeito de diferentes meios de cultura no isolamento de microrganismos

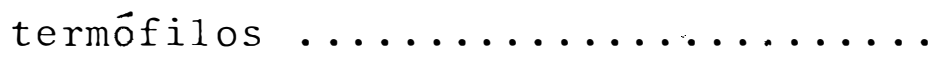


4.2.2. Frequência de fungos termófilos em pilhas de cavacos de eucalipto e em vărios pontos da fäbrica de pa-

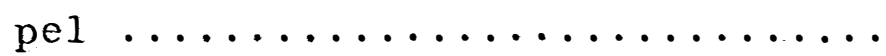

4.2.3. Avaliação das taxas de crescimento micelial dos fungos isolados, sob diferentes temperaturas .........

4.2.4. Avaliação do período latente de ger minação dos esporos de fungos isola dos, sob diferentes temperaturas...

4.2.5. Efeito de diferentes fontes de carbono no desenvolvimento de três fun gos termófilos isolados ..........

4.2.6. Avaliação do hidrolisado de madeiraăgar como meio de cultura para fun gos termófilos isolados de cavacos de eucalipto................... 58

4.3. Identificação dos fungos termófilos isolados da pilha de cavacos de eucalipto com auto aquecimento .....................6 60

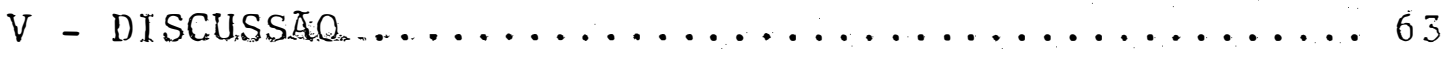

5.1. Monitoramento da pilha de cavacos .......66 63

5.2. Isolamento de fungos termófilos .........6 64

5.3. Crescimento de fungos termófilos em diferentes temperaturas ................66 66

5.4. Germinação de esporos de fungos isolados em diferentes temperaturas ............66 68

5.5. Crescimento de fungos isolados em ... algumas fontes de carbono ..................69 69

Vi - Conclusós $\ldots \ldots \ldots \ldots \ldots \ldots \ldots \ldots \ldots \ldots \ldots \ldots \ldots$

Vi I - Literatura CitadA $\ldots \ldots \ldots \ldots \ldots \ldots \ldots \ldots \ldots \ldots \ldots$ 


\title{
LEVANTAMENTO DE FUMGOS TERMÓFILOS \\ ASSOCIADOS A PILHAS DE CAVACOS DE Eucazyptus SPP.
}

\author{
AUTOR: Celso Garcia Auer \\ ORIENTADOR: Tasso Leo Krugner
}

\section{RESUMO}

o. isolamento de fungos termófilos a partir de cavacos de eucalipto apresentando auto-aquecimento, com temperatu ras máximas variando de $53-62^{\circ} \mathrm{C}$, mostrou a ocorrência de Asper gizzus sp., Dactylomyces thermoplhilus, Penicilzium bacizlusporum, Rhizomucor sp., Sporotrichum sp. e Thermoascus aurantiacus. Com exceção de $D$. thermophizus, estes fungos foram também isolados de solo de talhões florestais de eucalipto, do ar e de äguas residuais para lavagem de toras e da lagoa de tratamento de efluentes. Foram avaliadas as frequências relativas de cada fungo isolado, observando-se a ausência de padrôes definidos de distribuição nos pontos amostrados no decorrer do período de armazenamento. 
A análise das taxas de crescimento micelial,em meio BDA, nas temperaturas de $20,30,40,50,60$ e $70^{\circ} \mathrm{C}$ indicou as temperaturas ótimas de $30^{\circ} \mathrm{C}$ para Aspergizzus e P. bacizzisporum; $40^{\circ} \mathrm{C}$ para Rhizomucor e $50^{\circ} \mathrm{C}$ para $D$. thermophizus, sporotrichum e T. aurantiacus. Não houve crescimento nas temperaturas de 60 e $70^{\circ} \mathrm{C}$. A incubação de esporos em ägar-āgua a $20,30,40$ e $50^{\circ} \mathrm{C}$, mostrou que somente Aspergizzus, P. bacizzisporum e Rhizomucor apresentaram germinação de esporos a $20^{\circ} \mathrm{C}$. Os pontos ótimos de germinação dos conídios se aproximaram dos pontos ótimos de cres cimento micelial.

Foi avaliado o efeito de dextrose, sacarose, amido, hidrolisado de madeira e carboximetil celulose como fontes de carbono a Aspergizzus, Rhizomucor e T. aurantiacus. Não houve di ferenças significativas entre dextrose, sacarose e amido, porém estas fontes foram significativamente superiores ao hidrolisado de ma deira e çarboximetil celulose. O crescimento inadequado dos fungos nestas ültimas fontes de carbono sugere a sua incapacidade pa ra degradação de hemicelulose e celulose. 
.$x i$.

\section{SURVEY OF THERMOPHILIC FUNGI \\ ASSOCIATED WITH EUcalyptus spp. CHIP PILES.}

AUTHOR: Celso Garcia Auer ADVISER: Tasso Leo Krügner

\section{SUMMARY}

\section{Isolations of thermophilous fungi from}

self-heated chip piles of eucalypt wood, with maximum temperatures ranging from $52-63^{\circ} \mathrm{C}$, slowed the ocurrence of Aspergizzus sp., Lactyzomyces thermophilus, Penicillium bacillisporum, Rhizomucor sp., Sporotrichum sp. and Thermoascus aurantiacus. With exception of D. thermophizus, all fungi isolated from the pile were also isolated from eucalypt forest soil, air, mill waste water used for round wood washing and from water of the treatment lagoon of effluents.

The relative frequency of each thermophilous fungi isolated did not show regular distributional patterns in the sampling points and during the period of storage. 
Rates of mycelial growth on potato dextrose agar at the temperatures of $20,30,40,50,60$ and $70^{\circ} \mathrm{C}$ showed the optimum temperature for growth at $30^{\circ} \mathrm{C}$ for Aspergizzus and P. bacizlisporum; $40^{\circ} \mathrm{C}$ for Rinizomucor and $50^{\circ} \mathrm{C}$ for $D$. the $2^{\circ}$ ophizus, Sporotrichum and T. aurantiacus. Growth was not at 60 and $70^{\circ} \mathrm{C}$. The incubation of spores on water-agar at $20,30,40$ and $50^{\circ} \mathrm{C}$ showed that only Aspergizlus, P. bacillisporum and Rhizomucor germinate at $20^{\circ} \mathrm{C}$. The optimum germination points were similar to the optimum growth point.

The effects of glucose, sucrose, starch, hydrolysate of wood and carboxymethyl cellulose (CilC) as carbon sources on mycelial growth of Aspergizzus, Rhizomucor e T. aurantiacus were also studied. There were not signifjcant differences among glucose, sicrose and starch, but they were significantly better than hydrolysate of wood and. CMC. The inadequate growth on wood extract and CMC suggests the incapacity of these fungi to degrade hemicellulose and cellulose. 


\section{I - INTRODUCĀO}

O gênero Eucalyptus vem sendo utilizado, no Estado de São Paulo, como principal fonte de fibras curtas para a produção de celulose e papel, em florestas de curta rotação. Deste tipo de manejo resulta a produção de madeira com grande quantidade de alburno, que facilita o ataque de microrganismos (COWLING et alii, 1974). A estocagem da madeira na forma de cavacos, é uma alternativa de armazenamento para futuro processamento, que pode, porém, ter implicações microbiológicas, degradadoras ou não (ESLYN, 1973 e FERRARI \& KRUGNER, 1984).

Aquecimento interno em pilhas de cavacos de ma deira tem sïdo observado em vārias de celulose e papel (FOELKEL \&.ZVINAKEVICIUS, 1979 e LIMA et alii, 1980), ao qual devem estar associados vārios microrganismos, dentre eles os fungos ter mófilos (TANSEY, 1971 e FULLER, 1985). 


$$
0 \text { presente trabalho teve por objetivos: }
$$

1. verificar a ocorrência de auto-aquecimento em pilha de cavacos de Eucalyptus spp., armazenada ao ar livre;

2. isolar os fungos termófilos presentes na pilha de cavacos;

3. identificar os fungos termófilos isolados;

4. estudar a distribuição dos fungos termófilos dentro da pilha de cavacos, durante o período de armazenamento e;

5. estudar o efeito da temperatura e fontes de carbono no crescimento e/ou esporulação dos fungos isolados. 


\section{I - REVISÃO DE LITERATURA}

2.1. Armazenamento de madeira sob a forma de cavacos

A estocagem de cavacos, ao ar livre, em indústrias de celulose foi iniciada durante a década de 1950 nos EUA. Os cavacos, destinados à produção de celulose, eram resíduos de serrarias e de fäbricas de aglomerados. Suas vantagens durante - manejo do material e sua economia em custos, atrairam a atenção de outros países, tais como, Canadâ, Australia, Europa e Ja pão, que adotaram este sistema (BERGMAN, 1972).

ESLYN (1973) comparando os dois principais metodos de estocagem de maleira, como cavacos ou como toras, afir mou que a melhor alternativa para armazenamento de madeira seria na forma de cavacos. Certos aspectos como, por exemplo, 
maior facilidade no transporte do material, manejo dentro da fäbrica e maior economia de espaço, apresentam-se como mais favoráveis, em relação ao uso de toras (ENGEL,1985).

Desvantagens, também, são observadas nos pon tos relacionados com o aumento no teor de finos durante o manejo dos cavacos, contaminação dos cavacos com cinzas do ar e outros agentes que causam o aparecimento de pontos pretos no papel, e maior risco de ignição espontânea na pilha. LINDGREN e ESLYN (1961) opinaram que a quantidade de madeira deteriorada, na pilha de cavacos, pode ser a mesma ou maior do que com toras.

BERGMAN et alii (1970) relatam que a principal vantagem do armazenamento de cavacos ao ar livre está na minimi zação dos custos com manejo, mas apresentando perdas substanciais de madeira, da ordem de $1 \%$ por mês de estocagem. Os autores observaram, em contraste com esta perda, maior produção de polpa celulósica, a partir de cavacos de coníferas estocadas ao ar livre, sendo devido este fato ao decréscimo no teor de extra tivos da madeira.

HATTON (1970) estudando os efeitos do armazena mento com coníferas, verificou que podem ocorrer perdas na produção de celulose, com base na madeira armazenada, e redução da qualidade, além do aumento no consumo de produtos químicos duranté os processos de cozimento e branqueamento. As perdas econômicas mais elevadas, segundo o autor, aconteceriam em estocagens por períodos acima de 1 ano. 
Em condições atuais, a madeira destinada

produção de cavacos provém de florestas de curta rotação. (SIMOES et alii, 1980), as quais vão diretamente ao tambor de descascamento e ao picador.

COWLING et alii (1974) postulam o uso desta ma deira, pois a pilha fica constituída de cavacos com alto teor de umidade, com valores ao redor de $50 \%$, e de madeira com grande quantidade de alburno, material mais suscetível à deterioração por microrganismos e insetos. Em concordância FERNANDES (1977) estabeleceu que a madeira originada de florestas com menor idade de corte, apresenta alto conteúdo de madeira juvenil com baixa quantidade de cerne. Para folhosas, como o eucalipto, esta madeira possui maior conteúdo de lignina e composto fenóli cos, com menor teor de holocelulose e extrativos, quando comparados com os valores de uma madeira de árvore adulta; possui também, menor densidade e comprimento de fibras ligeiramente in ferior à madeira adulta, porém produzindo celulose de proprieda des similares.

Em ensaios mais diretos, HATTON \& HUNT estudaram a permanência de cavacos ao ar livre por 12 e 24 me ses, utilizando Picea grauca e Pinus contorta, verificando perdas na produção de polpa celulósica, acompanhadas pelo aumento no consumo de álcalis. Os autores estabeleceram que o período de permanência deve estar restrito a períodos com menos de 12 meses. Outras consequências do armazenamento foram discuti das por BERGMAN (1972), que relacionou o decréscimo nos teores 
de extrativos e resinas da madeira de coníferas, aumento da opacidade do papel que implicaria em maior consumo de produtos no braqueamento e perdas na resistência da polpa e do papel, pe 10 uso de cavacos com 3 a 4 meses de armazenamento ao ar 1 ivre.

\subsection{Características gerais dos microrganismos termófilos}

A termofilia, característica de crescimento em temperaturas acima das observadas no ambiente, relaciona - se com a capacidade genética de certos microrganismos em adaptar se seu desenvolvimento em direção às condições extremas do am biente (DOWDING,1981).

A pesquisa com microrganismos termófilos, de acordo com EMERSON (1968), foi iniciada no início deste século e sua constatação em meio de cultura, foi devida à incubação de material vegetal em estufas com temperaturas acima de $40^{\circ} \mathrm{C}$. Ain da segundo esse autor, foi concedido a Hugo Miehe o pioneirismo da investigação completa do fenômeno de auto-aquecimento de pilhas de feno, e pela realização dos primeiros estudos e anảli ses do fenômeno da termofilia e associação com os microrganis mos presentes. O estudo da ecologia por Noack, descreveu outros fungos, isolados novos, a partir de resíduos, tais como, esterco e restos de cultura (APINIS, 1967).

A origem da energia térmica liberada nos pro cessos de auto-aquecimento e sủa relação com a presença e ação 
de microrganismos foram profundamente estudadas por vărios pes quisadore's (WEDBERG \& RETTGER, 1941 e BARTHOLONEW \& NORMAN, 1953). De acordo com os resultados obtidos, os autores observaram modi ficações nas populações de microrganismos presentes, ocorrendo o surgimento de populações termöfilas durante a decomposição de materiais de origem vegetal, bem como, a elevação da temperatura. Houve correlação entre os valores máximos de temperatura e aqueles de $\mathrm{CO}_{2}$ liberados, mostrando boa probabilidade de termogênese biológica iniciar-se quando a matéria orgânica é constituída de compostos altamente energéticos (NORMAN et alii,1941).

Mais tarde, COONEY \& ENERSON (1964) reuniram o conhecimento adquirido até então e apresentaram a taxonomia, morfologia e biologia geral de fungos com caräter de crescimento em altas temperaturas, monografia que tem servido com auxí 1io à caracterização e identificação dos microrganismos. Em revisão feita por SAMSON (1981), às 13 espécies de fungos termofí licos classificadas por COONEY \& ENERSON (1964) foi estendida a 50 taxons, sendo a maioria das espécies pertencentes aos fungos imperfeitos (deuteromicetos), além de encontrarmos asconicetos e zigomicetos(mucorales). Entre os basidiomicetos, representantes são encontrados nos gêneros Coprinus e Phanerochaete.

A base do termofilismo não está completamente elucidada, pois värios pontos permanecem obscuros, principalmen te aqueles referentes ao crescimento em altas temperaturas, por vezes próximas de $60^{\circ} \mathrm{C}$, e o porque da falta de crescimento em 
temperaturas comuns, entre $15-25^{\circ} \mathrm{C}$. EMERSON (1968) não conseguiu relacionar a termofilia e algumas estruturas presentes nas células como por exemplo, diferentes pigmentos e proporção de nucleotídeos e as características do metabolismo dos fungos ter möfilos. Outras hipōteses foram levantadas para explicação do fenömeno, e CRISAN (1973) baseado no conhecimento sobre membranas celulares e sua função, postulou ser a termo-estabilidade ultraestrutural, a ūnica hipötese que poderia explicar a exis tência de fungos termofílicos e, que estes microrganismos teriam membranas celulares com pontos de fluidez e flexibilidade em temperaturas acima das encontradas para os fungos mesofili cos. Confirmando, SMITH (1981) afirmou que Mucor pusizzus pos sui membranas particularmente estāveis em altas temperaturas, co mo uma possível consequência da membrana celular com estrutura modificada e que por sua vez modificaria as atividades das enzi mas associadas.

Diferentes substratos podem ser utilizados durante o desenvolvimento de fungos termófilos restringindo-se, em grande parte, na decomposição de materiais orgânicos residuais nos processos de compostagem (KANE \& MULLINS, 1973), em resíduos de minas de carvão na Grã-Bretanha (EVANS,1971a), causando destruição de grãos em sistemas inadequados de armazenamento (FLANNIGAN, 1970 ;FLANNIGAN \& SELLARS, 1972) e no armazenamento de madeira sob a forma de pilha de cavacos em fäbricas de celulose (BJORKMAN \& HAEGER, 1963; BERGMAN, 1972; SMITH \& OFOSU-ASI EDU, 1972). A associação destes microrganismos e substratos or- 
gânicos estaria ligada a processos de rápida transformação de composto lignocelulósico a compostos mais simples, devido à altas taxas do metabolismo, como parte do sistema de produção de humus (JAIN et alii, 1979 e KIRK \& SHIMADA, 1985).

Outras ocorrências e relatos acerca de fungos termófilos tem sido relacionadas com sua presença no solo (GOCHENAUR, 1975; TANSEY \& JACK, 1976 e ELLIIS, 1980b), na a tmo fera (EVANS, 1972; HUDSON, 1973; SANDHU \& SINorH, 1985), em água aquecida proveniente de fontes geotérmicas e induštrias (TANSEY \& BROCK, 1978; ELLIS, 1980a) em associação com animais e seres humanos como agente patogênicos (AINSWORTH \& AUSTWICK, 1955; Co ONEY \& EMERSON, 1964; EMERSON, 1968), resultando em alergias respiratórias, nos casos mais simples e em maior gravidade, atacando o sistema nervoso (TANSEY et arii, 1979 e THÖRNQUIST \& LUNDSTRON, 1980) .

2.3. Pilhas de cavacos de madeira com auto-aquecimento

$$
\text { Os primeiros trabalhos discorrendo sobre }
$$
fenômeno de auto-aquecimento em pilhas de cavacos ao ar livre, foram registrados na década de 1960. ROT̄HROCK et alii (1961)ava liando os efeitos do armazenamento de cavacos de Pinus caribaea, observaram temperaturas da pilha, em sua porção interna, de até $60^{\circ} \mathrm{C}$ nas primeiras semanas e permanência deste valor por 5 me ses. 
Segundo os autores, incrementos sucessivos da temperatura e a falta de relação com a temperatura ambiente, in dicaram a geração de calor no interior da pilha. Temperaturas máximas de $63^{\circ} \mathrm{C}$ foram observadas por SOMSEN (1962) em estudos com cavaccs de Pinus em períodos de um ano de armazenamento e em concordância com ROTHROCK et alii (1961) que registrou a fal ta de mudança na produção de polpa, bem como, aumento na demanda de âlcali ativo. Os autores discutem que, de modo geral, não. foram afetadas as propriedades mecânicas e físicas da prilpa.

Posteriores ensaios desenvolvidos com Quereus sp. e Nyssa sp., mostraram comportamento semelhante de auto aquecimento. Pilhas de cavacos compactadas apresentaram menor deterioração, provave?mente fela meror quartidade de oxigênio disponível e as temperaturas internas não acompanharam os valores do ambiente, de moda que após 30 dias, a temperatura do cen tro de pilha de Quercus e Nysea chegou a $57^{\circ} \mathrm{C}$ e $44^{\circ} \mathrm{C}$, respectivamente (BOIS et alii, 1962). A anâlise da umidade dos cavacos indicou um gradiente na pilha, almentando na camada me.is exter na e decrescencio no interior, com posterior equilíbrio em toda a pilha, apôs 30 dias. Houve influência de grandes precipita ções pluvionétricas no teor de umidade final dos cavaccs. Con firmações do processo de aquecimento espontâneo em pilhas de ca vacos e aspectos similares foram efetuadas por SCHNIDT (1969) e TANSEY (1971). 
No Brasil, CARVALHO et azii (1969), em traba Tho pioneiro de armazenamento de cavacos de Eucalyptus ao ar livre dirante 7 meses, não observaram aumento da temperatura além dis valores presentes no ambiente. Por outro lado, LIMA et alii (1980) encontraxam em operação de estocagem de Pinus elzi ottii, temperaturas māximas ao redor de $60-65^{\circ} \mathrm{C}$, sem evidências de ataque intensivo às frações celulōsicas e perda do rendimento em polpa, após 8 semanas de estocagem ao ar livre.

A decomposição de materiais de crigem vegetal, Iigada a processos termogênicos, teni sido uma consequência da

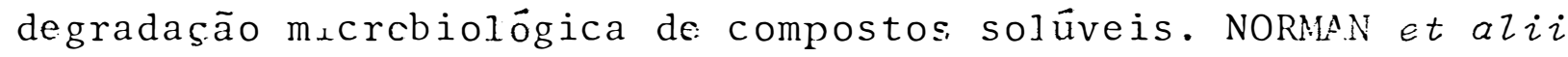
(1941) estudardo o processo de auto-aquecimento em palha de aveia, notaram que a remoção dos constituintes solūveis em āgua quente induzia a queda da taxa de elevação da temperatura e que a exaustão dos compostos nutritivos do substrato causou o térmi no da produção de calor. Houve uma taxa de elevação de calor, de acordo com os microrganismos presentes, e dois pontos máximos de calor prcduzidos sendo o primeiro ponto, devido à população mesôfila (crescimento à cemperatura ambiente) e, posteriormente - estabelecimento da população termöfila. Segundo os autores , existem enormes possibilidades da termogênese microbiológica, quando a matéria orgânica é rica em energia disponível.

Acompanhando o processo de auto-aquecimento, BERGMAN (1972) afirmou que o calor liberado dentro da pilha de cavacos, é causado principalmente pela respiração de células vi 
vas do alburno, dos microrganismos presentes e reaços químicas de oxidação que ocorrem no interior da pilha. A respiração de células do alburno, na pilha, decorrente da utilizaça de madei ra recëm-cortada, seria responsāvel pelo aumento de temperatura durante os primeiros dias, com a manutenção do calor devido ao metabolismo de compostos nutritivos promovido pelo crescimento de microrganismos e o superaquecimento devido a reações oxidati vas (HAJNY, 1966 e COWLING et alii, 1974). A ação direta dos mi crorganismos parece ser contraditöria e mais controversa è a determinação de que grupo participa ativamente, fungos ou bactê rias, explicando a elevação da temperatura nos níveis apresenta dos, FEIST et alii (1973a) discutiram que o início da termogê nia é derivada da respiração celular residual da madeira e da ocorrência de bactêrias, mesófilas, pois poucas colônias fúngicas foram isoladas de cavacos durante os sete primeiros dias de armazenamento. Seguindo a mesma linha de pensamento, ASSARSSON (1969) e BERGMAN (1972) relacionaram que as reservas nutricionais, na forma de amido e ăcidos graxos, em células de made ra, servindo como alimento as bactérias permitiram menos danos que os fungos, apesar destes $\vec{u} 1$ timos possuirem uma taxa de degradação extremamente lenta. Com estes aspectos abordados,è explicada pelo nümero de trabalhos desenvolvidos com fungos termö filos nos estudos de populações presentes em pilhas de cavacos, seu isolamento e avaliação dos efeitos sobre a madeira atacada (BERGMAN et alii, 1970; BERGMAN \& NILSSON 1971; OFOSU-ASIEDU \& 
SMITH, 1973a). SMITH (1975) afirmou que os fungos termófilos, associados a madeira, possuem como características principais, a falta de crescimento em temperatura ambiente, vivendo entre $37,8-60^{\circ} \mathrm{C}$, quando a temperatura da pilha e a alta umidade dos cavacos fornecem um habitat ideal para crescimento. Embora não existam evidências de que possam degradar a lignina, ułilizam a celulose, hemicelulose e extrativos como fonte de energia (FERGUS, 1969 e ROSENBERG, 1978).

A presença de reações químicas de auto-oxida ção e termogênese mostraram vârios efeitos na qualidade da madeira para a celulose, encontrados por FEIST et alii (1973b)ana lisando cavacos obtidos de madeira recêm-cortada de Populus tre muroides e Pseudotsuga menziesii, pasteurizados $\left(76\right.$ a $78^{\circ} \mathrm{C}$ por 48 horas) e conservados por 3 meses a $65^{\circ} \mathrm{C}$. Foram registradas perdas na produção de polpa ao redor de 21 a. $23^{\circ} \mathrm{C}$, alëm do maior requerimento de alcālis, maior teor de rejeitos na fábrica e decrêscimo das propriedades físicas e químicas da polpa na faixa entre 10 e $35 \%$. KUBLER (1982b) postulou que pequenas quan tidades de oxigênio nas cavidades celulares e entre cavacos de madeira poderiam reagir com compostos, gerando calor em : tentas oxidações internas e causar o aquecimento da pilha. O autor somente observou a proporcionalidade entre a geração de calor e a temperatura da pilha, apesar das condições da pilha apresenta rem normalmente total perda de calor para o ambiente. o baixo nível de oxigênio no interior da pilha foi atribuido, principal 
mente, ao consumo microbiológico, tendo como consequência a produção de calor. o consumo do oxigênio disponível aos organis mos vivos e a oxidação química direta, deixaria o oxigênio resi dual, de pouco efeito na liberação de calor.

A importância do armazenamento de cavacos ao ar livre e a ocorrência de auto-aquecimento estaria relacionada com os principais problemas para a industria, tais como, perdas em madeira e produção de polpa com base na quantidade armazenada, na qualidade da polpa produzida e aument́o de consumo durante a polpação e/ou produtos químicos durante o branqueamento da celulose (HULME \& HATTON, 1976a). Contudo, avaliando-se a fisio logia dos microrganismos termófilos, foi notado que a termogêne se biológica causou queda no teor de extrativos e segundo :HATTON (1970) o grau ou facilidade da remoção de lignina de Picea parece aumentar com o período de armazenamento prolongado, fato explicado por OFOSU -ASIEDU \& SMITH (1973b) que sugerir?m a capacidade de degradar os extrativos fenólicos e a lignina. A prọ dução de limo, caracterizada pela aglomeração da biomassa de microrganismos e residuos de resinas e gomas durante as etapas de produção de celulose e papel, discutida por ANGELIS \& SGA GLIA (1980) poderia ser incrementada pela presença de fungos e bactérias que atravessando o processo de cozimento, chegariam até a polpa e o papel (EVELEIGA \& BREMER, 1963). Porēm, BERGMAN (1972) postulou que o consumo de certos extrativos, ácidos gra- 
.15 .

xos insaturados e outros compostos insaponificáveis poderiam le var à diminuição de 1 imo formado, e consequentemente aumento na qualidade de polpa produzida. 


\section{III - MATERIAIS E MÉTODOS}

3.1. Montagem, monitoramento da pilha e coleta de cavacos de eucalipto.

A montagem da pilha de cavacos de madeira, no pátio da fábrica da Champion Papel e Celulose S/A, em Mogi Guaçu, SP., seguiu a metodologia utilizada pela mesma, onde sáo construídas, praticamente, duas pilhas de cavacos. Existe uma pilha maior, de forma trapezoidal (vista sob corte longitu dinal) com volume estimado entre 25.000 e $30.000 \mathrm{~m}^{3}$ de cavacos, servindo como base para outra pilha de forma cônica de volume bem inferior e muito variável, de acordo com o consumo indus- 
trial. A pilha maior mantëm o cavaco armazenado por 4 a 5 meses, enquanto que a pilha menor superposta abastece os digesto res industriais da fäbrica durante este período. Foi destinada ao estudo a pilha maior, pelo fato de permanecer mais tempo sob a influência do ambiente e dos microrganismos. Esta comeşou a ser construída em 09.06.84, sendo completada no dia 15.00.84, e mantida até fim de outubro/84, época em que se in ciou o consumo final dos cavacos. A pilha foi terminada em 05.11 .84$.

A madeira utilizada, para a montagem da pilha, constou de uma mistura de espëcies (Eucalyptus grandis, E. saligna e outras), sendo seus percentuais de participa b̧a volu métrica descritos na Tabela 1 , a partir de dados fornecidos pela fäbrica. Da tóra até a forma de cavacos, a madeira passou pelos processos de lavagem com äguas servidas do licor do cozi mento, descascamento, picagem e transporte por esteira ate o pätio de armazenamento. Os cavacos utilizados na montagem da pilha apresentaram diferentes espessuras, caracterizadas por uma faixa percentual do total da pilha, com seus valores apresenta dos na Tabela 2. De acordo com informa toos prestadas pela fäbrica, a utiliza tão deste sistema condicionava a reduções no teor de rejeitos, bem como melhor eficiência de cozimento para prodủçãó de celulose. 
Tabela 1 - Relação das espécies de Ecalyptus e sua participação em volume $\left(\begin{array}{l}0 \\ 0\end{array}\right)$, na montagem da pilha de cavacos de ma deira em Mogi Guaçu.

\begin{tabular}{lc}
\hline Espëcie & Participação em volume $\left(\begin{array}{l}0 \\
0\end{array}\right) *$ \\
\hline E. saligna & 56,3 \\
E. grandis & 42,1 \\
Outras * & 1,6 \\
\hline
\end{tabular}

* - Cerca de $84,2 \%$ da madeira é de 1 a rotação, com idade média ponderada igual a 8,1 anos.

** - Incluem-se as espêcies recebidas pela fábrica em menor quantidade: $E$. urophyl.za, E. robusta, etc.

Tabela 2 - Caracterização da espessura (mm) dos cavacos em faixas percentuais, produzidos pelo picador para a mon= tagem da pilha de cavacos em Mogi Guaçu.

$\begin{array}{llll}\text { abaixo de } & 4 & 80-85 \\ \text { entre } 4 \text { e } & 6 & 11-14 \\ \text { entre } 6 \text { e } 8 & 3-5 \\ \text { acima de } 8 & 0-12\end{array}$


Nas fases iniciais da montagem da pilha, foram demarcados os pontos para a amostragem inicial e mensal do arma zenamento, visando a coleta de cavacos e medição das temperaturas internas e externa:

O monitoramento da pilha fixou-se na determinação dos parâmetros em apenas um setor, pelo fato de que o aumento do número de pontos de amostragem levaria a um conflito com as atividades da indústria durante as operações de abastecimento.

A determinação de temperaturas foi obtida pelo uso de termopares de ferro-constantn, ligados a um registrado res de temperatura digital de fabricação nacional, marca ICos. Os termopares inseridos dentro de um tubo galvanizado, de modo que os fios elétricos não ficassem em contato com os cavacos, sendo todo o conjunto colocado na pilha, durante a montagem da pilha. O registrador de temperatura permaneceu do lado de fora da pilha, no qual foram efetuadas as leituras, às 8 horas da manhã, das temperaturas presentes na pilha e no ambiente externo, e cuja disposição é mostrada pela Figura 1 .

A precipitação mensal foi registrada, sendo os dados fornecidos pela Champion, atravēs de medições locais efetuadas em pluviômetros pertencentes à empresa. 


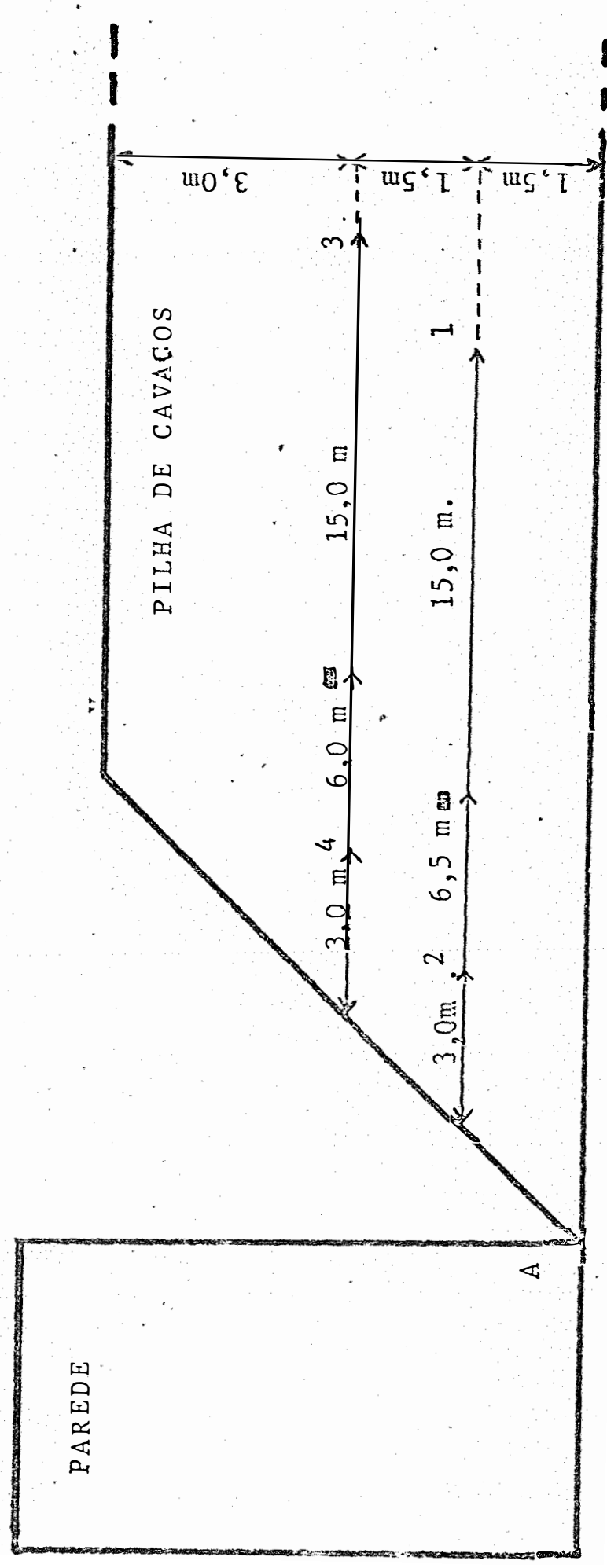

$\stackrel{8}{8}$

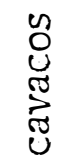

ช

莺

茞

苋

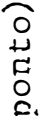

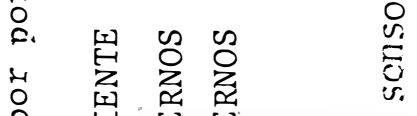

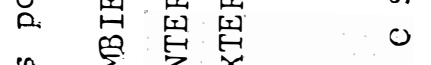

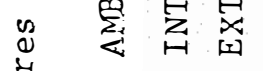

$\begin{array}{llll}4 & 4 & 1 & 1 \\ 0 & \vdots & 1 & 1 \\ 0 & 4 & m & \vdots\end{array}$

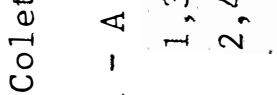

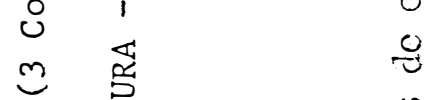

m

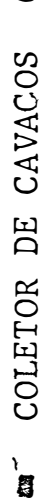

㝵

乐

됨 돔

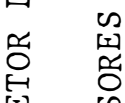


Os coletores de cavacos constaram de recipien tes construidos com tela de ferro e chapa de à so em formato cị lindrico, tendo a parte anterior aguda, onde soldou-se uma argola de ferro para tracionamento com cabos de a so, quando da sua retirada da pilha. O coletor possuia em sua parte posterior uma abertura, com tampo parafusado, para a coloca sáo e re tirada dos cavacos. Estes amostradores, em nümeros de seis, fo ram preenchidos com $10 \mathrm{Kg}$ de cavacos e colocados dentro da pi1ha, prevendo-se a retirada de 2 por mês. O coletor delineado conforme a Figura 2 foi baseado em estudos relacionados com a estocagem de cavacos ao ar livre (BJORKMAN e HAEgER, 1963; TANSEY, 1971; SMITH \& OFOSU-ASIEDU, 1972). Os cavacos coletados foram acondicionados em sacos plásticos de polietileno e fechados pạ ra se evitar a perda de umidade e rapidamente despachados o la boratörio do Depto: de Ciências Florestais (determinatoóes físicas) e o laboratório de Fitopatologia (determina sooes microbiolögicas) da ESALQ/USP.

A determina şã da umidade foi efetuada pela pesagem prëvia dos cavacos úmidos, secagem em estufa a tempera tura de $10 \mathrm{I} \pm 5^{\circ} \mathrm{C}$ por 12 horas, no minimo, e posterior pesagem, obtendo-se a umidade percentual pela seguinte förmula:

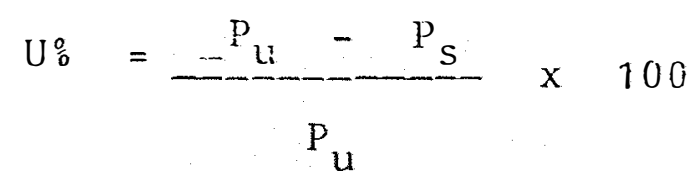




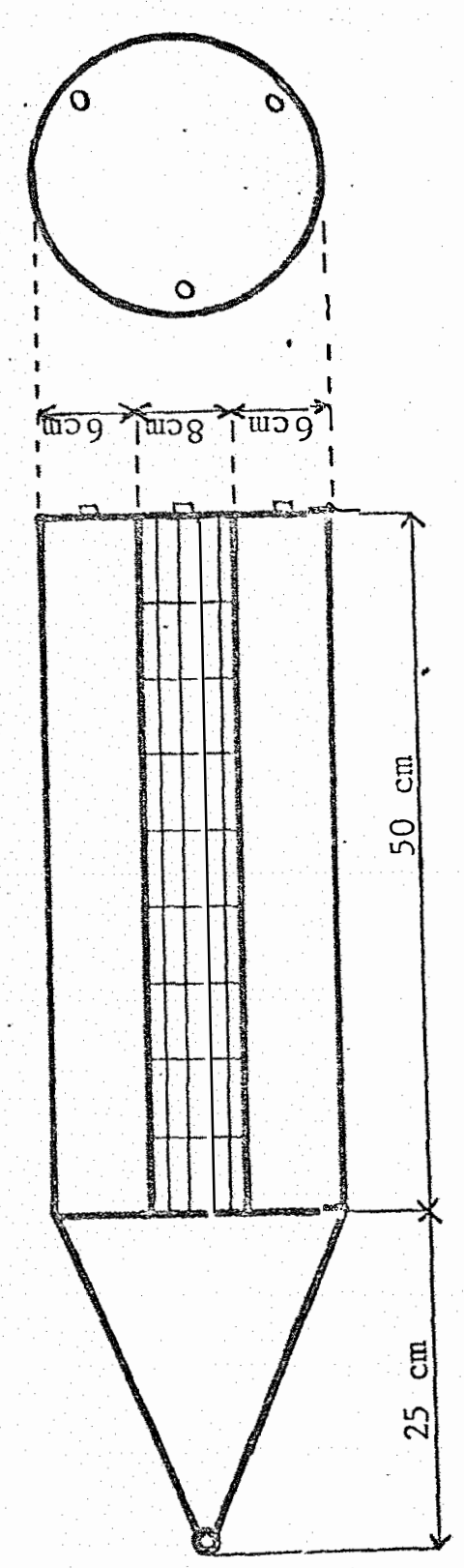

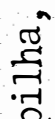

ठृ

통

密

怘

๘

윽

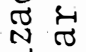

겅

点。

ल)

只

तब

ญ đ

त्ञ है

ช

in 0

.

उै ष्ष

잉

芩

응

ชี

1

芯 
onde:

$$
\begin{aligned}
& \mathrm{P}_{\mathrm{u}}=\text { peso dos cavacos ümidos }(\mathrm{g}) \\
& \mathrm{P}_{\mathrm{S}}=\text { peso dos cavacos secos (g) }
\end{aligned}
$$

A obtenção dos valores de $\mathrm{pH}$ dos cavacos cole tados foi baseada e adaptada dos trabalhos de HULME e HATTON (1976b). Pesou-se $100 \mathrm{~g}$ de cavacos ümidos, que foram colocados e um frasco de Erlenmeyer de $500 \mathrm{ml}$, juntamente com $200 \mathrm{~g}$ de ăgua destilada de pH entre 6,0-6,5. Todo o conjunto foi colocado em agitação, por uma hora, sendo o líquido filtrado e feita a medicão dos valores em peagâmetro digital. 
3. 2. Atividades conduzidas no laboratörio

3.2.1. ENSAIO 1 - Teste com diferentes meios de cultü ra pura para isolamento de microrganismos termófilos.

Cavacos de eucalipto foram coletados no dia v6.04.84, a partir de uma pilha da fäbrica, anterior à destina da para os estudos da distribuição dos microrganismos, visando-se testar o mëtodo de isolamento. Da pilha de cavacos com auto-aquecimento, con 4 meses de armazenamento ao ar livre, retiram-se cavacos de locais onde a temperatura registrada foi igual ou acima de $40^{\circ} \mathrm{C}$, na profundidade entre $1,0-1,5 \mathrm{~m}$ da superficie da pilha.

A têcnica de isolamento utilizada foi a de implantação de tecidos internos do cavaco en meio de cultura. Apös esterilização externa dos cavacos, pela flambager com ālcool (imersão em álcool $92^{\circ} \mathrm{G}$. L. e queima), foran extraídos tecidos con dimensoes em torno de 2 - $3 \mathrm{~mm}$ de espessura e $1 \mathrm{ar}-$ gura, com 8 - $10 \mathrm{~mm}$ de comprimento. De cada cavaco, retiraramse 3 partes do tecido interno, uma para cada meio de cultura, sendo distribuidas 4 partes por placa de Petri, perfazendo cada meio 25 placas, totalizando a amostragem de 100 cavacos, ao acaso. 
Os meios de cultura empregados para o ensaio, extraídos de BOOTH (1971), foram meio BDA (extrato de $200 \mathrm{~g}$ de batata; dextrose, $20 \mathrm{~g}$; ä̧ar-ägar, $18 \mathrm{~g}$ e ägua destilada q.s.p. $1000 \mathrm{ml}$ ), nutrienté-ágar (NA) (peptona comercial, $5,0 \mathrm{~g}$; extrato de carne, 3,0 g; ágar-ägar, $18 \mathrm{~g}$ e ägua destilada q.s.p. $1000 \mathrm{ml}$ ) e meio de Martin modificado (peptona comercial, $15 \mathrm{~g} ; \mathrm{MgSO}_{4} \cdot 7 \mathrm{H}_{2} \mathrm{O}$, $0,5 \mathrm{~g} ; \mathrm{K}_{2} \mathrm{HPO}_{4}, 1,0 \mathrm{~g}$; rosa bengala , 0,035 g; sulfato de estrep tomicina, 1:10.000; dextrose, $10 \mathrm{~g}$; ägar-ägar, $20 \mathrm{~g}$ e ägua des tilada q.s.p. $1000 \mathrm{~m} 1)$.

As placas inoculadas foram colocadas para incuba sâo $\epsilon$ m estufa controlada para $50^{\circ} \mathrm{C}$ e mantidas por 48 horas, sendo posteriormente efetuada a determinacão da frequência de microrganismos isolados.

3.2.2. ENSAIO 2 - Comparação entre BDA e hidrolisado de madeira-ägar para isolamento de fun gos termöfilos.

Como meio de isolamento foram utilizados o meıo BDA, de composição idêntica ao Ensaio 1, hidrolisado de madei ra-ägar (ana). O licor de madeira resultou do cozimento de ca vacos de eucalipto em ägua destilada a $170^{\circ} \mathrm{C}$, obtendo-se um extrato de madeira com $86,8 \%$ de açücares totais (método fẹnolsulfürico) após neutralização com NaOH $1 \mathrm{~N}$, pH igual a 7,0 . 
O meio HMA foi elaborado pela adi'são de ăgar a um volume do ex trato, correspondente a $20 \mathrm{~g}$ de a cucares totais(hidrolisaco de mid deira, $230 \mathrm{ml}$; ăgar-ägar, $18 \mathrm{~g}$ e ägua destilada q.s.p. $1000 \mathrm{ml}$ ). Partindo-se de cavacos coletados na saída do picador e de cavacos do mesmo lote do Ensaio 1 , foram separados 100 cavacos ao acaso. De cada cavaco foram retirados dois peda şos de tecido, sem esterilizaţáo superficial, e colocados cada peda so em um meio de isolamento. Todo o conjunto foi incu bado em estufa controlada a $50^{\circ} \mathrm{C}$ por 48 horas, sendo posterior mente efetuada a identifica çäo cos fungos e sua frequência nos cavacos amostrados.

3.2.3. Isolamento de fungos termófilos a partir dos cavacos coletados da pilha.

O material coletado na fäbrica e traasportado em sacos plästicos foi prontamente processado, sendo as amostras coletadas e ha a analisadas, conservadas em câmara fria a $12^{\circ} \mathrm{C}$.

A metodologia para isolamento constou de dois tipos, com e sem esteriliza'são externa (Ensaio 1 e 2 ).

O primeiro lote de cavacos coletado para isolamento, constituiu-se de cavacos recém-picados, retirados dos pontos de amostragem da temperatura durante a construşão da pi 
1ha. A avalia são da incidência de microrganismos termöfilos foi efetuada com 24,48 e 72 horas de incubatao em meio BDA a $50^{\circ} \mathrm{C}$. Os lotes subsequentes compunham-se de cavacos, armazena dos ao ar livre, retirados dos coletores aos 34,64 e 95 dias de estocagem na pilha e uma coleta final manual ao 149 dias de armazenamento. Foram homogeneizados e separados 100 cavacos ao acaso, por ponto de coleta. A avalia sao da incidência dos fun gos termófilos foi feita com 24 horas de incubação em meio BDA a $50^{\circ} \mathrm{C}$.

Os fungos isolados foram transferidos para tu bos de ensaio com meio BDA e armazenados dentro de câmara fria para futuros estudos taxonômicos e fisiolögicos.

3.2.4. Isolamento de fungos termöfilos em vários pontos da fäbrica.

A principal finalidade desta sërie de ativida des foi a detecção cas possíveis fontes de inóculo de fungos termófilos.

Solos sob talhões florestais foram coletados, através da raspagen da camada de 2 a $\bar{c} \mathrm{~cm}$ da superficie, em vá rios pontos do talhao, totalizando $100 \mathrm{~g}$. O solo amostrado foi acondicionado em sacos de polietileno, selados, transportados e mantidos sob refrigeração $\left(5^{\circ} \mathrm{C}\right)$ atê o momento do plaqueamen- 
to. Segundo metodologia de Gochenaur (1975), foi efetuado o plaqueamento de solo em ăgar fundente colocando-se $1,0 \mathrm{~g}$ de so 10 em placa de Petri estéril, juntamente, com 1,0 ml de ägua destilada estëril para se efetuar a mistura entre os dois. So bre esta mistura foram vertidos $25 \mathrm{ml}$ de meio de Martin funden te $\left(40-45^{\circ} \mathrm{C}\right)$, cuja composişão. foi descrita no Ensaio 1. Foram amostrados 4 talhöescomerciais, formados por Eucalyptus, em Mogi Gua şu, SP., e 5 talhões em São Sinão, SP.. Para acada talhões foram feitos 3 plaqueamentos de solo, correspondendo a 3 placas.

Foi efetuada a coleta dos esporos presentes no ar, em pontos próximos à pilha de cavacos da fábrica, pela exposição de placas de Petri com meio de Maxtin por $10 \mathrm{mi}$ nutos (SANDHU \& SINGH, 1985).

A água para lavagem das toras e da lagoa de tratamento de efluentes industriais, devido à sua proximidade da pilha, foram analisadas para determinação da presença de fungos termófilos. A partir de $1000 \mathrm{ml}$ de água coletada na fá brica, retirou-se a aliquota de $1,0 \mathrm{ml}$ que, transferida para placas de Petri com meio de Martin, foi espalhada com uma al sa de Drigalski flambada com älcool.

Todas as placas inoculadas foram. incubadas, por 72 horas em estufas controladas a $50^{\circ} \mathrm{C}$, sendo efetuada ao final da incubação, a avaliação qualitativa dos fungos termófi los nos referidos substratos. 
3.2.5. ENSAIO 3-Determina saó de taxas de crescimento micelial dos fungos termófilos em diferentes temperaturas.

Dos isolados preservados em tubos de BDA foram separados 3 isolados de cada gênero, para se cobrir a varia'são natural entre os mesmos.

O meio de cultura utilizado para o ensaio foi - BDA. A inocula şáo constou da transferência de um disco de micêlio vegetativo, com $6 \mathrm{~mm}$ de diâmetro, retirado de placas de BDA com culturas puras dos fungos, para o centro das placas. Os discos foram retirados dos bordos de colônias incubadas a $40^{\circ} \mathrm{C}$.

As placas, após a inocula säo, foram incubadas em estufas controladas a $20,30,40,50,60$ e $70^{\circ} \mathrm{C}, \mathrm{com}$ as duas $\vec{u}$ timas temperaturas exigindo o emprego de cubas de vidro com chuma şo de algodão únido no seu interior, sendo todo o con junto colocado dentro da estufa. Este procedimento visou evitar a desseca șão räpida do meio pela a şao da alta temperatura (BKOCK \& ROSE, 1969).

Fez-se a avalia ção do crescimento micelial, atṛavés da medição da taxa de crescimento linear da colônia do fungo, quando a colônia se apresentava com os bordos distanciando-se de 1,0 a $1,5 \mathrm{~cm}$ dos bordos da placa. Efetuou-se a me- 
di şão de dois diâmetros perpendiculares entre si para obten taao do diâmetro mẻdio. Para se conseguir a taxa de crescimento di vidiu-se o diâmetro médio da colônia pelo tempo de incuba são, com os valores sendo expressos em $\mathrm{mm} / \mathrm{h}$.

Cada isolado possuia ¿ repeti jooes, correspondendo cada repeti.şão a uma placa de Petri.

3.2.6. ENSAIO 4 - A valia.saó da germiná'sâo dos esporos de fungos termófilos em diferen tes temperaturas.

Para análise do efeito da temperatura requer da, pelos fungos termófilos, para germina'são cios propágulos, utilizou-se como parâmetro de estudo, o período latente de ger mina șão, tempo mínimo requerido para início da germina şa o cu da menor percentagem de germira sáo , em uma dada temperatura (COCHRANE, 1958).

O método foi adaptado do teste de germina şa de esporos de GATTANI (1954). Em placas de Petri com culturas esporulantes puras, foram colocados $9 \mathrm{ml}$ de ägua destilada estéril e gentilmente raspadas com uma al ça de Drigalski flambada em álcool, obtendo-se uma suspensão de esporos cuja concentra.são foi determinada com o auxilio de hemacitômetro í câmara de Neubauer). Com a ajuda de uma pipeta estéril, foi transfe- 
rỉda uma alíquota da suspensão, contendo aproximadamente $10^{8}$ esporos, para cada placa de Petri com ägar-āgua (ăgar-āgar, 18 g e ảgua destilada q.s.p. $1000 \mathrm{ml}$ ), sendo espalhada pela superficíe do meio sôlido com al ça de Drigalski flambada.

De cada fungo foram estudados os $\bar{I}$ isolados, com cada isolado tendo 4 placas, repetições para as diferentes temperaturas, que foram colocados para incuba ção em estufas controladas a $20,30,40$ e $50^{\circ} \mathrm{C}$. A avaliação da germinação ob serva şáo em microscópio ötico em ocular de menor aumento $(100 \mathrm{x})$, foi efetuada em períodos de 2 em 2 horas.

\subsubsection{ENSAIO 5 - Avalia são do efeito de diferentes fontes de carbono no desenvolvimen- to de três fungos termófilos.}

Partindo-se de um meio base, no qual foram adicionadas várias fontes de carbono, avaliou-se os seus efe tos no crescimento micelial dos gêneros isolados: Aspergizlus, Rhizomucor e Thermoascus. Para produção de inöculo, foram retirados da câmara fria, repicados para placas com meio BDA e incubados a $40^{\circ} \mathrm{C}$.

A composição do meio foi baseada em meio míni mo para Neurospora; apresentado por SUSSMAN (1974). Para a preparação cio meio mínimo foram empregadas 3 soluçōes estoques 
(Tabela 3 ). A elabora são dos meios foi desenvolvida pela padronizaçào e adição de $20,0 \mathrm{~g}$ de carboidratos por litro de meio de cultura, sendo utilizados dextrose, sacarose, amido, carboximetil celulose e hidrolisado de madeura, com 18,0g de ágar-ägar e $20,0 \mathrm{ml}$ da soluşao estoque de meio mínimo.

As placas de Petri com os meios de cultura fo ram inoculadas com discos de micêlio vegetativo com $9 \mathrm{~mm}$ de diâmetro e incubadas em estufa controlada a $40^{\circ} \mathrm{C}$. O desenvolvimento dos microrganismos foi avaliado pela taxa de crescimen to micelial da colônia, em mm/h, como já descrito no Ensaio após um período de 24 horas de incuba são.

O delineamento experimental foi inteiramente casualizado, no esquema fatorial $3 \times 6$, com 4 repetisôes, correspondendo cada repeti şa lima placa de Petri. 
Tabela 3 - Soluções estoque para elabora são do meio mínimo Composityaio.

Solu !şão 1

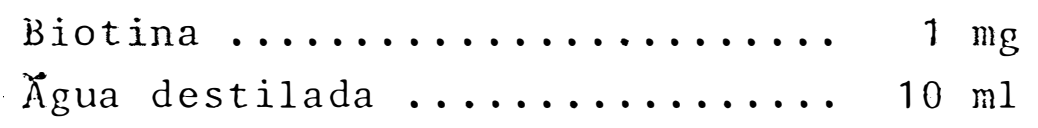

Solu'são 2

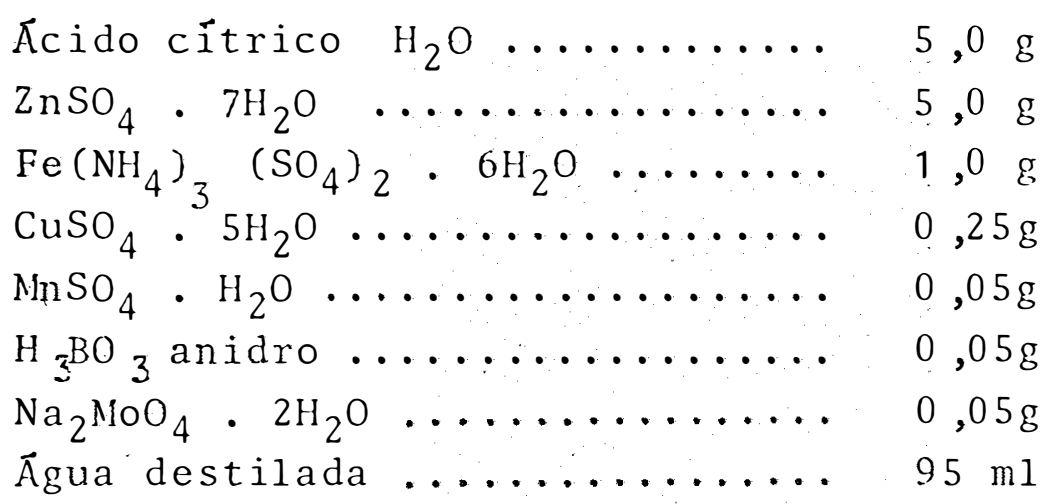

Meio Mínimo - Estoque

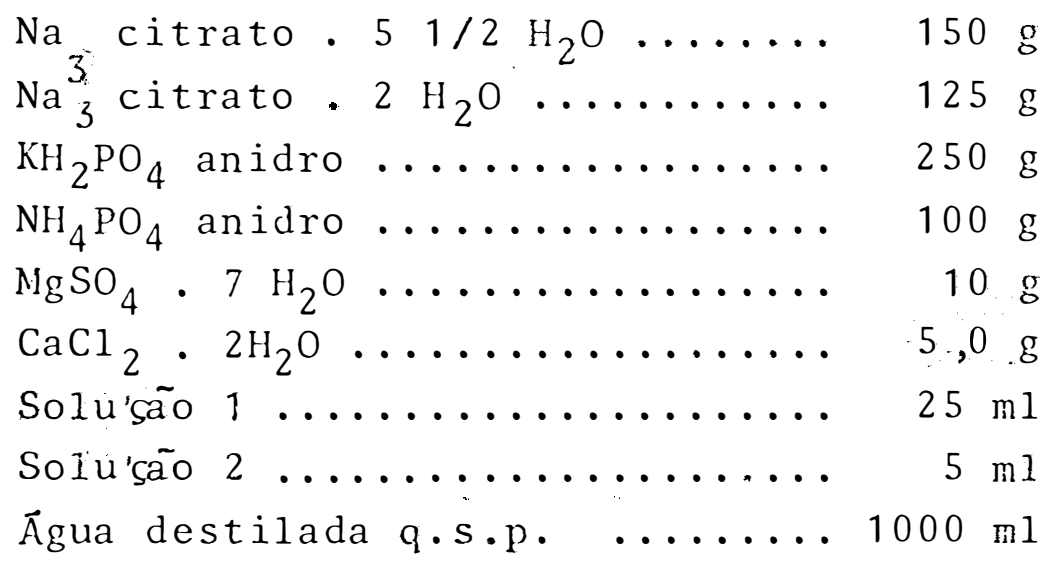


3.2.8. ENSAIO 6 - Teste do hidrolisado de madeira-ägar como meio de cultura para fungos termóf filos isolados de cavacos de eucalinto.

o procedimento nara obtenção do hidrolisado de madeira e elabora sáo do HMA são os mesmos do Ensaio 2 . Foram utilizados os sêneros Asperaizlus, Rhizomucor, Snorotrichum, PE nicillium e Thermoascus para estudo do meio HiA como meio para cultivo de fungos termófilos. O inóculo constou de discos de micêlio vegetativo com $9 \mathrm{~mm}$ de diâmetro, retirados de culturas puras em BDA e transferidos para o centro de placas, que foram incubadas em estufas controladas a $40^{\circ} \mathrm{C}$.

A avalia baó do crescimento micelial foj feita como no Ensaio 5, obtendo-se a taxa de crescimento micelial em $\mathrm{mm} / \mathrm{h}$, após um período de 24 horas de incuba são.

C delineamento experimental foi inteiramente ca sualizado, com cada gênero tendo 4 repeti.5oés, correspondendo cada repetiţão a uma placa de Petri.

3. 3. Identifica ţão dos fungos termófilos isolados.

A identifica'ção dos fungos isolados de cavacos de madeira foi desenvolvida e completada pela condução de trabalhos, em conjunto com o Instituto de Botânica - SP. Processou-se a identifica ção tendo por base a literatura atê o 
.35 .

presente momento, enquanto haviam sido efetuados contatos com outros especialistas em taxonomia, no exterior, para maiores indicatsões ou informa sões para a confirma são da identidade dos isolados. 


\section{IV - RESULTADOS}

4.1. Monitoramento das condições da pilha

A temperatura dos pontos à $15 \mathrm{~m}$ de profundida de mantiveram-se mais altas, do que as temperaturas dos portos a $3 \mathrm{~m}$, estes ültimos com valores iniciais próximos da temperatú ra ambiente (Tabela 4). Com o decorrer do tempo, as temperatu ras destes pontos mais externos tornaram-se inferiores às obser vadas no ambiente. Notou-se uma grande variação nos valores internos, acompanhando a variação do ambiente e a precipitação mensal (Tabela 5). A relação entre as temperaturas e a precipitação mensal, demonstra um distinto decréscimo nas temperaturas médias mensais da pilha de modo mais pronunciado nos pontos externos da pilha, sendo que no mês de outubro com a diminuição da precipitação, houve elevação da temperatura (Figura 3). 
Tabela 4 - Evolução da temperatura ambiente e nos pontos internos da pilha de cavacos de Eucalyptus armazenados ao ar livre.

\begin{tabular}{|c|c|c|c|c|c|}
\hline \multirow{3}{*}{ DATA } & & \multicolumn{4}{|c|}{ Temperatura $\left({ }^{O} \mathrm{C}\right)$} \\
\hline & \multirow{2}{*}{ Ambiente } & \multicolumn{4}{|c|}{ Pontos internos* } \\
\hline & & 1 & 2 & 3 & 4 \\
\hline $13 / 06$ & 37 & 36 & 43 & - & - \\
\hline $14 / 06$ & 31 & 36 & 43 & 34 & 29 \\
\hline $15 / 06$ & 37 & 36 & 45 & 40 & 37 \\
\hline $18 / 06$ & 41 & 36 & 49 & 47 & 48 \\
\hline $19 / 06$ & 34 & 34 & 48 & 47 & 48 \\
\hline $20 / 06$ & 41 & 36 & 52 & 50 & 43 \\
\hline $22 / 06$ & 36 & 35 & 50 & 49 & 53 \\
\hline $25 / 06$ & 40 & 36 & 33 & 53 & 56 \\
\hline $27 / 06$ & 40 & 39 & 26 & 55 & 54 \\
\hline $28 / 06$ & 25 & 38 & 22 & 54 & 50 \\
\hline $29 / 06$ & 35 & 41 & 23 & 58 & 49 \\
\hline $02 / 07$ & 34 & 47 & 21 & 58 & 33 \\
\hline $04 / 07$ & 33 & 54 & 22 & 49 & 26 \\
\hline $10 / 07$ & 38 & 57 & 31 & 51 & 24 \\
\hline $11 / 07$ & 36 & 58 & 32 & 47 & 24 \\
\hline $12 / 07$ & 40 & 60 & 34 & 42 & 25 \\
\hline $13 / 07$ & 37 & 60 & 3.3 & 38 & 24 \\
\hline $19 / 07$ & 32 & 60 & 23 & 35 & 28 \\
\hline $30 / 07$ & 38 & 56 & 22 & 41 & 31 \\
\hline $10 / 08$ & 35 & 52 & 24 & 44 & 27 \\
\hline $15 / 08$ & 28 & 50 & 29 & 45 & 27 \\
\hline $22 / 08$ & 20 & 48 & 16 & 45 & 23 \\
\hline $28 / 08$ & 26 & 47 & 26 & 47 & 23 \\
\hline $31 / 08$ & 29 & 48 & 25 & 48 & 25 \\
\hline $06 / 09$ & 34 & 48 & 23 & 50 & 25 \\
\hline $10 / 09$ & 32 & 48 & 23 & 52 & 25 \\
\hline $12 / 09$ & 39 & 49 & 25 & 56 & 26 \\
\hline $17 / 09$ & 34 & 49 & 23 & 56 & 26 \\
\hline $28 / 09$ & 28 & 52 & 33 & 58 & $\begin{array}{l}29 \\
35\end{array}$ \\
\hline $10 / 10$ & 40 & 55 & 34 & 60 & $\begin{array}{l}35 \\
37\end{array}$ \\
\hline $15 / 10$ & 38 & 56 & 30 & 60 & $\begin{array}{l}37 \\
38\end{array}$ \\
\hline $17 / 10$ & 43 & 55 & 29 & 60 & 38 \\
\hline $22 / 10$ & 44 & 59 & 33 & $\begin{array}{l}62 \\
63\end{array}$ & $\begin{array}{l}36 \\
34\end{array}$ \\
\hline $29 / 10$ & 42 & 60 & 30 & 03 & 34 \\
\hline
\end{tabular}

* Pontos internos: $1-15 \mathrm{~m}$ profundidade e $1 \mathrm{~m}$ de altura do solo $3-15 \mathrm{~m}$ profundidade e $3 \mathrm{~m}$ de altura do solo 2 - $3 \mathrm{~m}$ profundidade e $1 \mathrm{~m}$ de altura do solo 4 - 3 m profundidade e $3 \mathrm{~m}$ de altura do solo 
Tabela 5 - Precipitação mensal (mm) observada na fäbrica da Champion Papel e Celulose S/A em Mogi Cinacu, SP., du rante o período de armazenamento.

\begin{tabular}{lcc}
\hline MES & Precipitação mensal (mn) \\
\hline Junho & 5 \\
Julho & 113 \\
Agosto & 81 \\
Setembro & 9 \\
Outubro & 127 \\
Novembro & \\
\hline
\end{tabular}

A umidade dos cavacos indicou a manuten ção da umidade em teores pröximos, nos pontos amostra dos, durante o armazenamento ao ar livre (Tabela 6). Notou-se uma leve tondência para perda de unidade com o decorrer do tem po de armazenamento, havendo pequenas eleva'sões do teor de umidade no ponto mais externo da pilha, aposs 64 e 149 dias, devido a ocorrência de precipita'soes nos meses de agosto e novembro, respectivamente aos 60 e 150 dias de estocagem.

Com rela'ção ao pH da solúção obtida dos cavacos, foi observada a tendência do decréscimo nos valores do pH com o aumento do período de armazenamento e que os menores valo res foram encontrados no ponto mais interno da pilha (Tabela ?). 

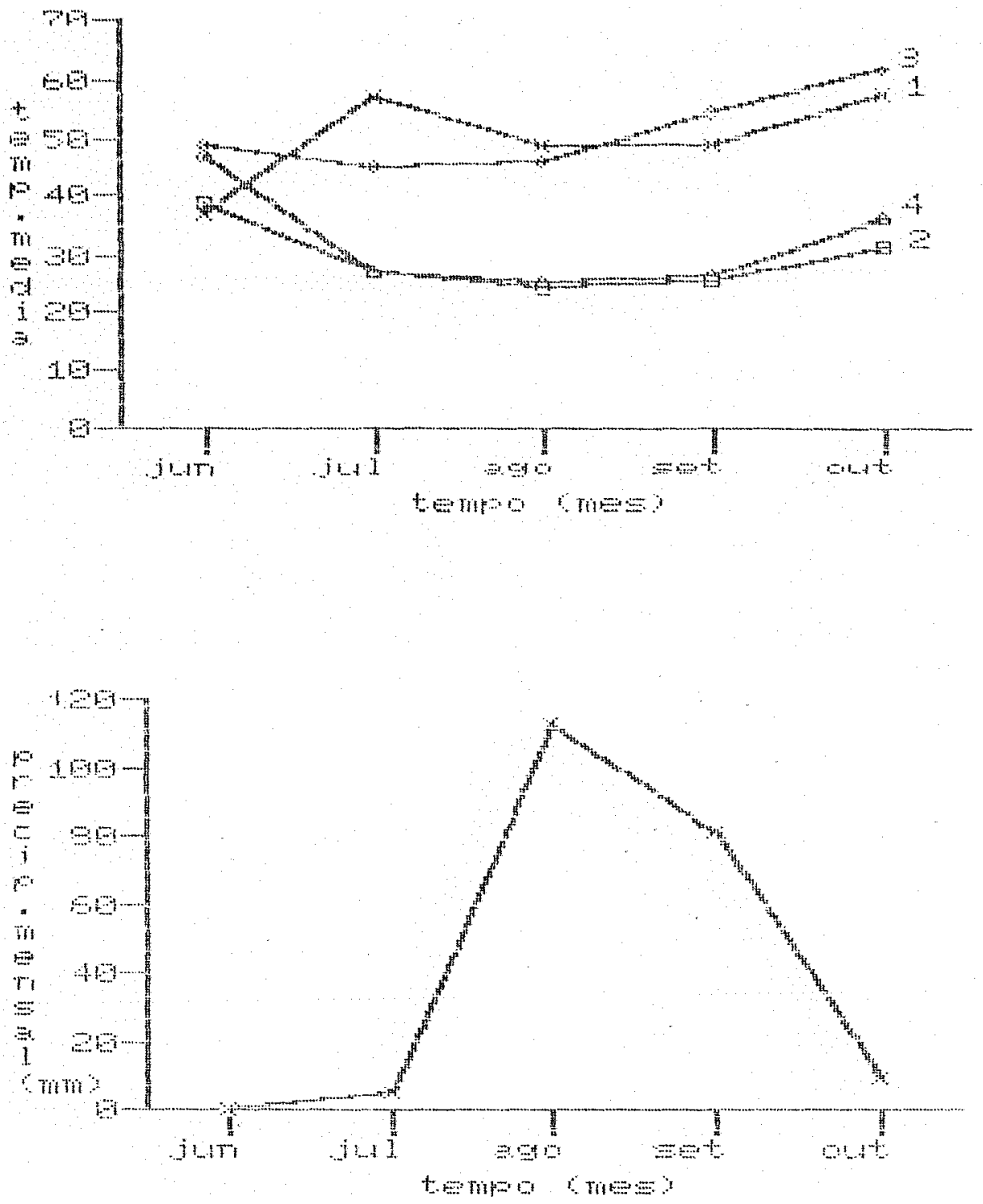

SENSORES DE TEMPERATURA

$1-15 \mathrm{~m}$. de profundidade e $1,5 \mathrm{~m}$, de altura do solo $3-15 \mathrm{~m}$. de profundidade e $3 \mathrm{~m}$. de altura do solo 2 - $3 \mathrm{~m}$. de profundidade e $1,5 \mathrm{~m}$. de altura do solo 4 - $3 \mathrm{~m}$. de profundidade e $3 \mathrm{~m}$. de aktura do so 1 o

FIGURA 3 - Relação entre as temperaturas médias mensais $\left({ }^{\circ} \mathrm{C}\right)$, nos pontos de amostragem e a precipitação mensal (mm) na pilha de cavacos de eucalipto. 
Tabela 6 - Teores médios* da umidade dos cavacos $\left(\begin{array}{l}0 \\ 0\end{array}\right)$ coletados em dois pontos internos da pilha de cavacos de eucalipto, durante o armazenamento ao ar livre, em Mogi Guaçu, SP.

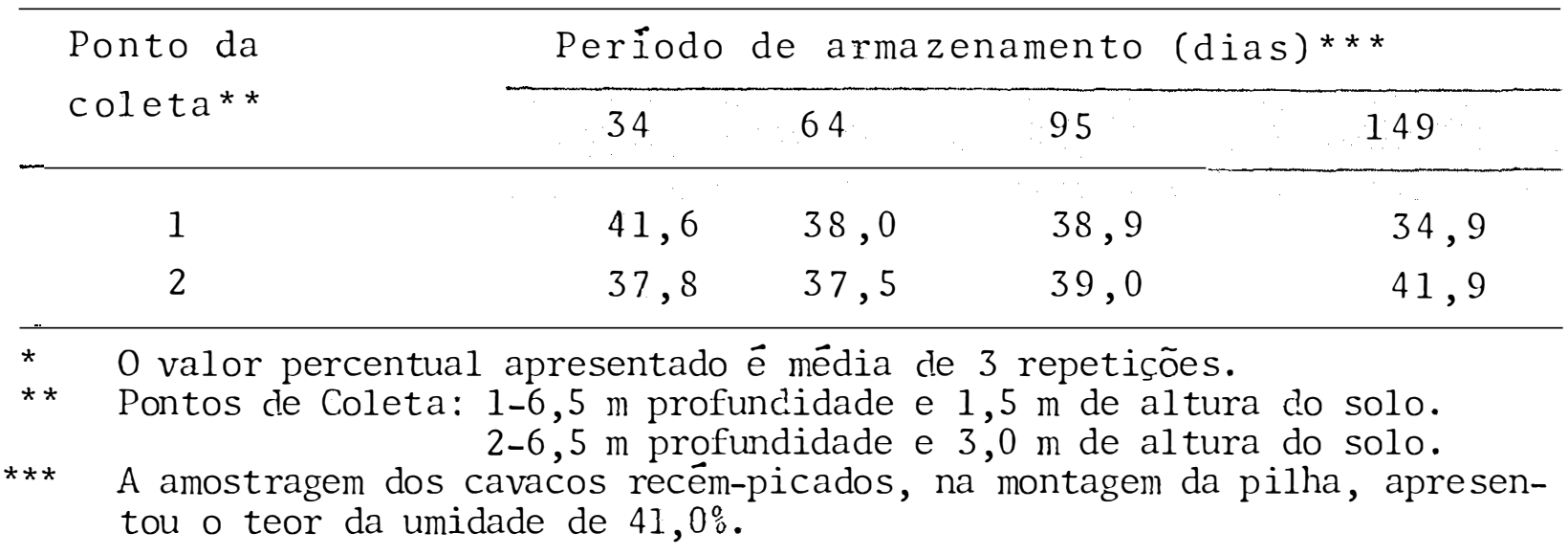

Tabela 7 - Valores médios* de pH obtidos dos cavacos coletalos em dois pontos internos da pilha de cavacos de eucalipto, durante o armazenamento ao ar livre, em Mogi Guaçu, SP.

\begin{tabular}{ccccc}
\hline \multirow{2}{*}{$\begin{array}{c}\text { Ponto da } \\
\text { coleta** }\end{array}$} & \multicolumn{3}{c}{ Periodo de } & \multicolumn{3}{c}{ armazenamento (dias)*** } \\
\cline { 2 - 5 } & 34 & 64 & 95 & 149 \\
\hline 1 & 3,63 & 3,72 & 3,66 & - \\
2 & 4,00 & 3,90 & 3,84 & - \\
\hline
\end{tabular}

* 0 Valor absoluto apresentado é média de 3 repetições.

* Fontos de coleta: 1 - 6,5 m profundidade e 1,5 m de altura do solo. 2 - 6,5 m profundidade e 3,0 $\mathrm{m}$ de altura do solo. *** A amostragem dos cavacos recém-picacos, na montagem da pilha, apresentou o valor médio do $\mathrm{pH}$ de 4,05. 


\subsection{Atividades conduzidas no laboratório}

4.2.1. Efeito de diferentes meios de cultura no isolamento de microrganismos termófilos.

A avalia são cio Ensaio 1 revelou diferentes

frequências para os nicrorganismos termöfilos, fungos e bactérias, surgidos a partir dos cavacos de madeira,nos três meios de cultura estudados (Tabela 8). Comparando-se os substratos, observou-se que o meio Nutriente-ägar apresentou a maior quanti dade média de isolados, bem como um maior número de bactérias termófilas sem alterar a frequência de fungos isolados em BDA. O meio de Martin apresentou decréscimo na frequência dos micror ganismos, em reláşão aos anteriores, pela presença de sulfato de estreptomicina e rosa bengala em sua composi taáo.

No Ensaio 2, a compara são do meio BDA contra o meio HMA, foi avaliada pelas frequências de microrganismos ter mófilos (Tabela 9) e as frequências dos gêneros de fungos termó filos (Tabela 10), isolados de cavacos recém-picados e armazena dos por 4 meses. Foi registrado um número quantitativa e quali tativamente menor de microrganismos termófilos em BDA, em qualquer dos lotes de cavacos amostrados. 
Tabela 8 - Frequência de microrganismos termófilos (\%) isolados, a partir de cavacos de eucaliptos armazenados ao ar livre, em três meios de cultura incubados a $50^{\circ} \mathrm{C}$ por 48 horas.

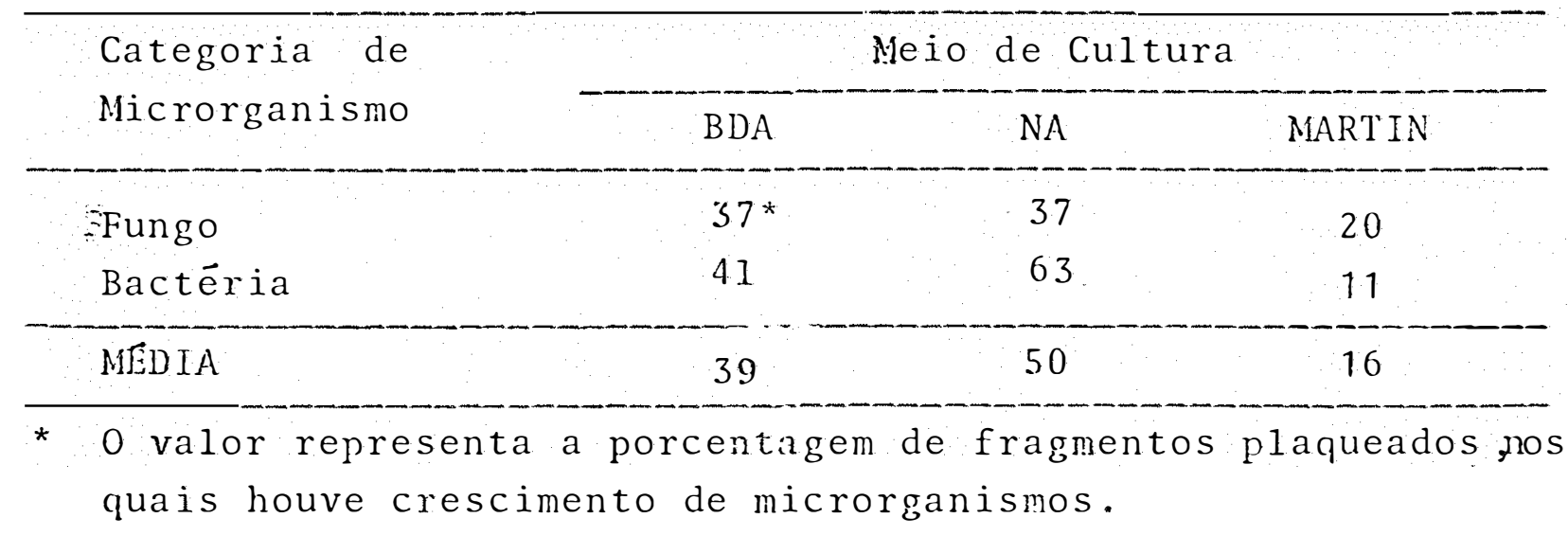

Tabela 9 - Frequência de colônias bacterianas e de gêneros de fungos termöfilos $\left(\frac{\circ}{0}\right)$, isolados de dois lotes de cavacos de eucalipto, incubados em BDA e HMA a $\quad 50^{\circ} \mathrm{C}$ por 48 horas.

\begin{tabular}{|c|c|c|c|c|}
\hline \multirow{2}{*}{\multicolumn{2}{|c|}{$\begin{array}{l}\text { Meio de } \\
\text { Cultura }\end{array}$}} & \multirow[b]{2}{*}{ Nicrorganismos } & \multicolumn{2}{|c|}{ CAV ACOS } \\
\hline & & & Recēm-Picados & ヘramazenados* \\
\hline \multirow{2}{*}{\multicolumn{2}{|c|}{ LMA }} & Fungo & $0 * *$ & 2 \\
\hline & & Bactēria & 0 & 0 \\
\hline \multirow{2}{*}{\multicolumn{2}{|c|}{ BDA }} & Fungo & 2 & 5 \\
\hline & & Bactēria & 0 & 2 \\
\hline * & $\begin{array}{l}\text { Os cavacos } \\
\text { gem. }\end{array}$ & foram coletados & de uma pilha com 4 & meses de estoca \\
\hline ** & $\begin{array}{l}\text { o valor rep } \\
\text { quais houve }\end{array}$ & $\begin{array}{l}\text { presenta a porcen } \\
\text { e crescimento de }\end{array}$ & $\begin{array}{l}\text { tagem de fragmentos } \\
\text { microrganismos. }\end{array}$ & plaqueados, nos \\
\hline
\end{tabular}


Tabela 10 - Discriminasáo dos gêneros de fungos termófilos e respectiva frequência $\left(\begin{array}{l}0 \\ 0\end{array}\right)$ isolados a partir de dois lotes de cavacos de eucalipto, incubados em BDA e HMA por 48 horas.

\begin{tabular}{|c|c|c|c|}
\hline $\begin{array}{l}\text { Mieio de } \\
\text { Cultura }\end{array}$ & $\begin{array}{l}\text { Lote de } \\
\text { Cavacos }\end{array}$ & Fungos & Frequência $(\%)$ * \\
\hline \multirow{3}{*}{ HMA } & Recêm-picados & nenhum fungo isolado & \\
\hline & Armazenados & Aspergizlus sp. & 1 \\
\hline & & Penicillium bacillisporum & 1 \\
\hline \multirow{6}{*}{$\mathrm{BDA}$} & Recêm-picados & $\begin{array}{l}\text { Aspergillus sp. } \\
\text { Penicillium bacillisporum }\end{array}$ & \\
\hline & \multirow{5}{*}{ Armazenados } & Aspergizlus sp. & 84 \\
\hline & & Rhizomucor sp. & 19 \\
\hline & & Sporotrichum sp. & 2 \\
\hline & & Penicillium bacillispomm & 54 \\
\hline & & Thermoascus aurantiacus & 2 \\
\hline
\end{tabular}

* O valor representa a porcentagem de fragmentos plaqueados, nos quais houve crescimento de microrganismos. 
4.2.2. Frequência de fungos termöfilos em pilhas de cavacos de eucalipto e em vários locais próximos da fábrica de papel.

O levantamento da incidência de microrganismos termófilos na pilha de cavacos da fábrica, tomou por base de amostragem cavacos recém-picados e cavacos com vários períodos de armazenamento. A avalia'são cias placas de meio de cultura inoculadas com os cavacos, foi efetuada após 72 horas de incubatsão a $50^{\circ} \mathrm{C}$, visando impedir auto-contaminatsoés de fungos com alta taxa de esporulásáo e räpido crescimento micelial, bem como o problema de ressecamento do meio. Dos quatro pontos amostrados, apenas três apresentaram fungos, bactérias e leveduras em baixa e constante incidência (Tabela 11). Os gêneros de fungos identificados foram: Sporotrichum $\left(2 \frac{\circ}{\circ}\right)$ no ponto 2 e $(1 \%)$ no ponto 3, e Penicilliumbacillisporum ( $4 \%$ ) no ponto 4.

A análise dos cavacos estocados mostrou uma grande variaţao ra frequência de microrganismos nas diversas épocas de amostragem. O número de bactërias e leveduras termóf las isoladas foi maior, em média, quando os cavacos foram flambados com âlcool, independentemente do ponto de coleta (Tabela 12). Foram registradas aos 64 e 95 dias, as maiores porcentagens de isolamento e posterior queda nos valores no isolamento efetuado aos 149 dias, este ültimo período apresentando porcen tagens similares às encontradas com 34 dias de estocagem. Para os 
fungos isolados observou-se claramente, o efeito da esterilizasão externa no isolamento e a falta de un padra cie distribui.̧̧ão ciurante o período de armazenamento (Tabela 13 ). Os fungos Aspergizzus e sporotrichum foram os mais frequentes nos dois métodos de isolamento e como Rhizomucor apresentaram dininui'ção no número de isolados quando da esterilizaţão externa. Com Dactyzomyces thermophizus foram observados valores medios de frequências similares, com ou sem esteriliza'sầ, e como P.baci Zisporum, mostrou menor nümero de isolados a partir do ponto mais interno, onde haviam sido registrados as maiores temperatu ras (Tabela 4). Thermoascus aurantiacus foi isolado em maior quantidade em cavacos flambados, com baixa incidência em cavacos não esterilizados, demonstrando um provāvel efeito negativo ao crescimento ou maior espesificidade para desenvolvimento no in terior do cavaco.

Foi estudada em conjunto, a presen sa de fungos termófilos em solos de forma toóes florestais de Eucalyptus, e dentro da fäbrica, nas äguas residuais para lavagem de toras e da lagoa de tratamento de efluentes e no ar adjacente à pilha de cavacos (Tabela 15). Aspergizzus e P. bacizzisporum foram os fungos de maior ocorrência, sendo registrados no solo, nas äguas residuais e no ar. Todos os fungos estiveram presentes no solo coletado, com excețo äe $D$. thermophizus que nao foi isolado na fábrica, mas ocorreu em isolamentos efetuados com cavacos da pilha. 
Tabela 11 - Incidência ( $\left.\begin{array}{l}0 \\ 0\end{array}\right)$ de microrganismos termófilos isolados de cavacos de eucalipto recém-picados e flambados em àlcool, retirados de 4 pontos na pilha e incubados em meio BDA, a $50^{\circ} \mathrm{C}$ por 72 horas.

\begin{tabular}{|c|c|c|c|c|}
\hline \multirow{2}{*}{ Nicrorganismos } & \multicolumn{2}{|c|}{ Ponto } & \multicolumn{2}{|c|}{ coleta } \\
\hline & 1 & 2 & 3 & 4 \\
\hline Bactérias e leveduras & 3 & 2 & 6 & 5 \\
\hline Fungos & 0 & 2 & 4 & 1 \\
\hline Cavacos sem microrganismos & 97 & 96 & 90 & 94 \\
\hline
\end{tabular}

* Ponto de coleta: 1 - $15 \mathrm{~m}$ profundidade e 1,5 $\mathrm{m}$ de altura do solo. 2 - $15 \mathrm{~m}$ profundidade e $3 \mathrm{~m}$ de altura do solo. $33 \mathrm{~m}$ profundidace e $1,5 \mathrm{~m}$ de altura do solo. 4 - $3 \mathrm{~m}$ profundidade e $3 \mathrm{~m}$ de altura do solo.

Tabela 12 - Incidência $\left(\begin{array}{l}0 \\ 0\end{array}\right)$ de bactérias e leveduras termófilas em cavacos de Eucalyptus em vários períodos de arma zenamento, a partir de dois pontos internos da pilha, sob dois métodos de isolamento e incuba ção em BDA por 24 horas à $50^{\circ} \mathrm{C}$.

\begin{tabular}{|c|c|c|c|c|c|c|}
\hline \multirow[b]{2}{*}{$\begin{array}{l}\text { Ponto de } \\
\text { coleta * }\end{array}$} & Período & de & arma & hamento & (dia) & \multirow[b]{2}{*}{ Média } \\
\hline & $\begin{array}{l}\text { Métodos de } \\
\text { Isolamento ** }\end{array}$ & 34 & 64 & 95 & 149 & \\
\hline \multirow{2}{*}{1} & E & 6 & 90 & 26 & 12 & 33,5 \\
\hline & $N$ & 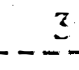 & 24 & 81 & 2 & $-27,5$. \\
\hline \multirow{2}{*}{2} & $E$ & 11 & 99 & 34 & 13 & 39,3 \\
\hline & $N$ & 0 & 24 & 70 & 5 & 24,8 \\
\hline
\end{tabular}

* Ponto de coleta: 1 - 6,5 $\mathrm{m}$ profundidade e $1,5 \mathrm{~m}$ de altura do solo.

$2-6,5 \mathrm{~m}$ profundidade e $3 \mathrm{~m}$ de altura do solo.

* Nétodo de isola E - cavaco flambado externamente en álcool. mento: $\quad \mathrm{N}$ - cavaco não flambado. 
Tabela 13 - Frequência $\left(\begin{array}{l}0 \\ 0\end{array}\right)$ dos fungos termófilos em dois pontos internos da pilha de cavacos de Eucalyptus, com vários períodos de armazenamento, isolados de cavacos flambados e incuba são em BDA por 72 horas e $50^{\circ} \mathrm{C}$.

\begin{tabular}{|c|c|c|c|c|c|c|}
\hline \multirow{2}{*}{ FUNGOS } & \multirow{2}{*}{$\begin{array}{l}\text { Ponto de } \\
\text { coleta * }\end{array}$} & \multicolumn{4}{|c|}{$\begin{array}{l}\text { Período de armaze- } \\
\text { namento (dias) }\end{array}$} & \multirow{2}{*}{ Média } \\
\hline & & 34 & 64 & 95 & 149 & \\
\hline \multirow[t]{3}{*}{ Aspergiz.zus sp. } & 1 & 48 & 35 & 31 & 30 & 36,0 \\
\hline & 2 & 19 & -6 & -2 & -2 & 7,3 \\
\hline & 1 & 0 & 0 & 4 & 5 & $2, \pi$ \\
\hline D.thermophizus & 2 & 6 & 0 & 41 & 0 & 11,8 \\
\hline \multirow[b]{2}{*}{ Rhizomucor sp. } & 1 & 1 & 1 & 0 & 0 & 0,5 \\
\hline & 2 & 2 & 0 & 0 & 0 & 0,5 \\
\hline \multirow[b]{2}{*}{ sporotrichum s } & 1 & 34 & 12 & 41 & 24 & 27,8 \\
\hline & sp. 2 & 45 & 14 & 37 & 1 & 24,3 \\
\hline \multirow[b]{2}{*}{ P.bacillisporum } & 1 & 3 & 0 & 23 & 25 & 12,8 \\
\hline & 2 & $5 \underline{3}$ & 1 & 27 & 30 & 27,8 \\
\hline \multirow[b]{2}{*}{ T.aurantiacus } & 1 & 44 & 0 & 9 & 52 & 26,3 \\
\hline & 2 & 2 & 0 & 20 & 35 & 14,3 \\
\hline
\end{tabular}

* Ponto de coleta: 1 - 6,5 m profundidade e $1,5 \mathrm{~m}$ de altura do solo. $2-6,5 \mathrm{~m}$ profundidade e 3 inde altura do solo. 
Tabela 14 - Frequência $\left(\begin{array}{l}0 \\ 0\end{array}\right)$ dos fungos termófilos em dois pontos internos da pilha de cavacos de Eucalyptus, com värios períodos de armazenamentos, isolados de cavacos rão flambados e incuba ção em BDA por 72 horas a $50^{\circ} \mathrm{C}$.

\begin{tabular}{|c|c|c|c|c|c|c|}
\hline \multirow[t]{2}{*}{ FUNGOS } & \multirow[t]{2}{*}{$\begin{array}{l}\text { Ponto de } \\
\text { coleta* }\end{array}$} & \multicolumn{4}{|c|}{$\begin{array}{l}\text { Período de armaze- } \\
\text { namento (dias) }\end{array}$} & \multirow[t]{2}{*}{ Média } \\
\hline & & 34 & 64 & 95 & 149 & \\
\hline \multirow[b]{2}{*}{ Aspergizlus sp. } & 1 & 78 & 96 & 100 & 100 & 93,5 \\
\hline & $\ldots$ & 96 & 100 & 84 & 0 & 70,0 \\
\hline \multirow[b]{2}{*}{ D. thermophitus } & 1 & 5 & 0 & 1 & 0 & 1,5 \\
\hline & -2 & 7 & $-\underline{0}$ & 47 & 0 & 13,5 \\
\hline \multirow{2}{*}{ Rhizomucor sp. } & 1 & 39 & 22 & 1 & 6 & 17,0 \\
\hline & $--\frac{2}{-}$ & 54 & ---5 & -2 & 0 & 15,3 \\
\hline \multirow{2}{*}{ Sporotrichum sp. } & 1 & 1.1 & 34 & 82 & 21 & 37,0 \\
\hline & --2 & 49 & 81 & -94 & 0 & 56,0 \\
\hline \multirow[b]{2}{*}{ P.bacillisporum } & 1 & 45 & 1 & 1 & 4 & 12,8 \\
\hline & $--\frac{2}{-}$ & -99 & 2 & 7 & 97 & 51,5 \\
\hline \multirow{2}{*}{ T. aurantiacus sp. } & 1 & 6 & 0 & 0 & 0 & 1,5 \\
\hline & 2 & 0 & 0 & 3 & 4 & 1,8 \\
\hline
\end{tabular}

* Ponto de coleta: 1 - 6,5 m profundidade e 1,5 m de altura do solo. 2 - 6,5 m profundidade e $3 \mathrm{~m}$ de altura do solo. 
.49 .

Tabela 15 - Ocorrência de fungos termófilos, em solos de talhóes florestais e em três pontos da fäbrica, isolados em meio de Martin e incubado por 72 horas a $50^{\circ} \mathrm{C}$.

\begin{tabular}{|c|c|c|c|c|c|}
\hline $\begin{array}{l}\text { Fungos } \\
\text { Isolados }\end{array}$ & $\begin{array}{l}\text { Talhoes } \\
\text { i Gua gu }\end{array}$ & $\begin{array}{c}\text { Florestais } \\
\text { São Sinão }\end{array}$ & $\begin{array}{l}\text { Agua } p / \text { lava } \\
\text { gem das to- } \\
\text { ras ** }\end{array}$ & $\begin{array}{l}\text { Lagoa de trata } \\
\text { mento de eflu- } \\
\text { entes } * *\end{array}$ & $\begin{array}{l}\text { Coleta de } \\
\text { Esporos } \\
\text { do ar ** }\end{array}$ \\
\hline Aspergizzus sp & 2 & 4 & + & + & + \\
\hline D. thermoptizius & - & - & - & - & - \\
\hline Rhizomucor sp & 2 & 1 & - & + & + \\
\hline Sporotrichum sp & - & 1 & - & + & - \\
\hline P.bacilliporum & 2 & 3 & + & + & + \\
\hline T.aurantiacus & 2 & 3 & - & - & + \\
\hline
\end{tabular}

* Foram amostrados talhoes de Eucalyptus en Mogi Gua cu - SP (4) e em São Simão - SP (5), sendo indicado o nümero de talkóes, onde o fungo foi isolado.

* * Indica ção .do fungo:

+ : presente

- : ausente 
4.2.3. Avalia'são das taxas de crescimento micelial dos fungos isolados, sob diferentes temperaturas.

Com base nos valores obtidos, pode-se verificar a existência de diferen ças entre as taxas de crescimento ótimo com os fungos estudados (tabelas 16 a 21). Para Aspergizzus e P. bacizlisporum seu ponto ótimo de crescimento foi $30^{\circ} \mathrm{C}$, enquanto que Rhizomucor demonstrou melhor crescimento a $40^{\circ} \mathrm{C}$. D. thermophilus, Sporotrichum e T. aurantiacus apresentaram maiores taxas de crescimento a $50^{\circ} \mathrm{C}$. Coincidentemente, os gêneros com crescimento a $20^{\circ} \mathrm{C}$ possuiam pontos ótimos de temperatura mais baixos que as temperaturas da pilha, com taxas de crescimento a $50^{\circ} \mathrm{C}$ bem inferiores aos outros fungos termófilos. Por outro lado, os fungos com ótimo de temperatura a $50^{\circ} \mathrm{C}$ não cresceram a $20^{\circ} \mathrm{C}$. Nâ houve crescimento dos fungos nas temperaturas de 60 e $70^{\circ} \mathrm{C}$ dentro do período de incuba tão. 
Tabela 16 - Taxas de crescimento micelial (mm/h) de isolados de Aspergilzus sp, incubados em BDA sob diferentes tem peraturas $\left({ }^{\circ} \mathrm{C}\right)$, até 9 dias.

\begin{tabular}{ccccc}
\hline $\begin{array}{c}\text { Temperatura } \\
\left({ }^{\circ} \mathrm{C}\right)\end{array}$ & Isolado 1 & Isolado 2 & Isolado 3 Média \\
\hline 20 & 0,28 & 0,29 & 0,27 & 0,28 \\
30 & 0,72 & 0,77 & 0,77 & 0,75 \\
40 & 0,79 & 0,63 & 0,42 & 0,61 \\
50 & 0,19 & 0,20 & 0,19 & 0,19 \\
60 & 0,00 & 0,00 & 0,00 & 0,00 \\
70 & 0,00 & 0,00 & 0,00 & 0,00
\end{tabular}

* Cada valor é média de 3 repetições e cada repetição corresponde a uma placa de Petri.

Tabela 17 - Taxas de crescimento micelial (mm/h) de isolados de D. thermophizus, incubados em BDA sob diferentes tem peraturas $\left({ }^{\mathrm{O}} \mathrm{C}\right)$, até 12 dias.

\begin{tabular}{ccccc}
\hline $\begin{array}{c}\text { Temperatura } \\
\left({ }^{\circ} \mathrm{C}\right)\end{array}$ & Isolado 1 & Isolado 2 & Isolado 3 Média \\
\hline 20 & 0,00 & 0,00 & 0,00 & 0,00 \\
30 & 0,44 & 0,50 & 0,36 & 0,43 \\
40 & 1,21 & 1,18 & 0,58 & 0,99 \\
50 & 1,24 & 1,31 & 1,22 & 1,26 \\
60 & 0,00 & 0,00 & 0,00 & 0,00 \\
70 & 0,00 & 0,00 & 0,00 & 0,00
\end{tabular}

* Cada valor é média de 3 repetições e cada repetição corresponde a uma placa de Petri. 
Tabela 18 - Taxas de crescimento micelial (mm/h) de isolados de P. bacizlisporum, incubados em BDA sob diferentes tem peraturas $\left({ }^{\circ} \mathrm{C}\right)$, até 9 dias.

\begin{tabular}{ccccc}
\hline $\begin{array}{c}\text { Temperatura } \\
\left({ }^{0} \mathrm{C}\right)\end{array}$ & Isolado 1 & Isolado 2 & Isolado 3 & Média \\
\hline 20 & $0,13^{*}$ & 0,12 & 0,12 & 0,18 \\
30 & 0,33 & 0,30 & 0,28 & 0,30 \\
40 & 0,29 & 0,25 & 0,30 & 0,28 \\
50 & 0,10 & 0,11 & 0,09 & 0,10 \\
60 & 0,00 & 0,00 & 0,00 & 0,00 \\
70 & 0,00 & 0,00 & 0,00 & 0,00
\end{tabular}

* Cada valor é média de 3 repetições e cada repetição corresponde a uma placa de Petri.

Tabela 19 - Taxas de crescimento micelial ( $\mathrm{mm} / \mathrm{h})$ de isolados de Rhizomucor sp, incubados em BDA sob diferentes temperaturas $\left({ }^{\circ} \mathrm{C}\right)$, até 9 dias.

\begin{tabular}{ccccc}
$\begin{array}{c}\text { Temperatura } \\
\left({ }^{\circ} \mathrm{C}\right)\end{array}$ & Isolado 1 & Isolado 2 & Isolado 3 & Média \\
\hline 20 & $0,84^{*}$ & 0,09 & 0,12 & 0,35 \\
30 & 1,91 & 1,09 & 1,52 & 1,51 \\
40 & 2,90 & 1,80 & 2,01 & 2,24 \\
50 & 2,05 & 1,58 & 2,42 & 2,02 \\
60 & 0,00 & 0,00 & 0,00 & 0,00 \\
70 & 0,00 & 0,00 & 0,00 & 0,00
\end{tabular}

* Cada valor é média de 3 repetições e cada repetição corresponde a uma placa de Petri. 
Tabela 20 - Taxas de crescimento micelial (mm/h) de isolados de sporotrichum sp, incubados em BDA sob diferentes tem peraturas $\left({ }^{\circ} \mathrm{C}\right)$, atē 12 dias.

\begin{tabular}{ccccc}
\hline $\begin{array}{c}\text { Temperatura } \\
\left({ }^{\circ} \mathrm{C}\right)\end{array}$ & Isolado 1 & Isolado 2 & Isolado 3 & Mëdia \\
\hline 20 & $0,00^{*}$ & 0,00 & 0,00 & 0,00 \\
30 & 0,52 & 0,45 & 0,39 & 0,45 \\
40 & 0,50 & 0,53 & 0,55 & 0,53 \\
50 & 0,69 & 0,74 & 0,61 & 0,63 \\
60 & 0,00 & 0,00 & 0,00 & 0,00 \\
70 & 0,00 & 0,00 & 0,00 & 0,00
\end{tabular}

* Cada valor é média de 3 repetições e cada repetição corresponde a uma placa de Petri.

Tabela 21 - Taxas de crescimento micelial (mm/h) de isolados de $T$, aurantiacus, incubados em BDA sob diferentes tem peraturas $\left({ }^{\circ} \mathrm{C}\right)$, até 12 dias.

\begin{tabular}{ccccc}
\hline $\begin{array}{c}\text { Temperatura } \\
\left({ }^{\circ} \mathrm{C}\right)\end{array}$ & Isolado 1 & Isolado 2 & Isolado 3 & Média \\
\hline 20 & $0,00^{*}$ & 0,00 & 0,00 & 0,00 \\
30 & 0,39 & 0,14 & 0,42 & 0,32 \\
40 & 3,68 & 4,03 & 3,81 & 3,95 \\
50 & 4,99 & 5,54 & 5,48 & 5,37 \\
60 & 0,00 & 0,00 & 0,00 & 0,00 \\
70 & 0,00 & 0,00 & 0,00 & 0,00
\end{tabular}

* Cada valor é média de 3 repetições e cada repetição corresponde a una placa de Petri. 
4.2.4. Avalia ção do período latente de germina são dos esporos de fungos isolados, sob diferentes temperaturas.

Com base no tempo gasto pelos esporos - para germina'são, foi determinado o período latente de germina cão dos fungos isolados em värias temperaturas (Tabela 22). Partindose das taxas ótimas de crescimento descritas no Ensaio 3, podese notar que os fungos Aspergizzus e P. bacizlisporum com crescimento micelial a $20^{\circ} \mathrm{C}$ foram os únicos fungos com esporos germinados nesta temperatura. No outro extremo, os fungos que cres ceram a $50^{\circ} \mathrm{C}$, D. thermophilus, Rhizomucor e T. aurantiacus, mostraram esporos germinados nesta temperatura.

A temperatura ótima de germina ção, determinada pelo menor período latente de germináção, de Aspergizzus, D. thermophilus e Rhizomucor foi a mesma da maior taxa de crescimento micelial. Com $P$. bacillisporum, a temperatura do menor período latente esteve acima da temperatura ótima de crescimento, enquanto que com $T$. aurantiacus houve o inverso. 0 fungo Sporotrichum apresentou problemas de germina'são, pois houve cres cimento a 30,40 e $50^{\circ} \mathrm{C}$ e somente germinatao a $30^{\circ} \mathrm{C}$. 
Tabela 22 - Período latente de germinalsão $(h)$ dos fungos termófilos isolados a partir da pilha de cavacos, em ägar-ägua. *

\begin{tabular}{lcccc}
\hline Fungos & \multicolumn{2}{c}{ Termperaturas } & $\left({ }^{\mathrm{O}} \mathrm{C}\right)$ & \\
\cline { 2 - 5 } & 20 & 0 & 40 & 50 \\
\hline Aspergizlus sp & $20-22$ & $6-8$ & $8-10$ & $58-60$ \\
D. thermophilus & $\mathrm{SG}^{* *}$ & $20-22$ & $12-14$ & $24-26$ \\
Rhizomucor sp & $68-70$ & $12-14$ & $2-4$ & $12-14$ \\
Sporotrichum sp & $\mathrm{SG}$ & $12-14$ & $\mathrm{SG}$ & $\mathrm{SG}$ \\
P. bacilzisporum & $44-46$ & $8-10$ & $6-8$ & $\mathrm{SG}$ \\
T. aurantiacus & $\mathrm{SG}$ & $20-22$ & $12-14$ & $24-26$ \\
\hline
\end{tabular}

* Os valores apresentados são médias de três isolados de cada fungo.

* $\quad \mathrm{SG}=$ Sem Germina t5ã 
4.2.5. Efeito de diferentes fontes de carbono no desen volvimento de três fungos termöfilos isolados.

O cultivo de Aspergizlus, Rhizomucor e $T$. aurantiacus em meio mínimo adicionado de vărias fontes de carbo no foi avaliado pelas taxas de crescimento micelial (mm/h) dos fungos estudados, cujos valores estão expressos na Tabela 22 .Não foram observados diferen ças entre meio mínimo com dextrose, sacarose e amido, pequena entre estes e meio mínimo simples, porém significativas quando em comparałão com hidrolisado de madeira e carboximetil celulose (CMiC). Cada fungo apresentou uma fonte de carbono preferencial para seu melhor desenvolvimento, registran do-se para Aspergitzus, Rhizomucor e $T$. aurantiacus, meio minimo com amido $(1,78 \mathrm{~mm} / \mathrm{h})$, dextrose $(2,31 \mathrm{~mm} / \mathrm{h})$ e amido $(1,28 \mathrm{~mm} / \mathrm{h})$, respectivamente. Sob outro ângulo, notou-se que o hidrolisado de ma deira e CMC foram as piores fontes de carbono, haja visto terem pro duzido as menores taxas de crescimento micelial, com os fungos estudados. 
Tabe1a 23 - Efeito de diferentes fontes de carbono no crescimen to de Aspergilzus, Rhizomucor e T.aurantiacus, em meio mínimo-ägar (MM) incubados por 24 horas a $40^{\circ} \mathrm{C}$.

\begin{tabular}{|c|c|c|c|c|}
\hline \multirow{2}{*}{$\begin{array}{l}\text { Meio de } \\
\text { cultura }\end{array}$} & \multicolumn{4}{|c|}{ Taxas de crescimento $(\mathrm{mm} / \mathrm{h})^{1}$} \\
\hline & \multicolumn{3}{|c|}{ Aspergillus s. Rhizomicor sp.T.aurantiacus } & - Média \\
\hline MM-Testemunha & 0,65 & 2,07 & 0,74 & $1,15 \mathrm{~A}$ \\
\hline MM-Dextrose & 0,74 & 2,31 & 0,69 & $1,25 \mathrm{AB}$ \\
\hline MM-Sacarose & 0,74 & 2,25 & 1,07 & $1,35 \mathrm{~A}$ \\
\hline MM-Amido & 0,78 & 2,13 & 1,28 & 1,39 A \\
\hline MM-Hidrolisado de madeira & 0,71 & 1,60 & 0,41 & $0,91 \mathrm{D}$ \\
\hline $\mathrm{MM}-\mathrm{CMC}$ & 0,63 & 1,75 & 0,39 & $0,92 \mathrm{CD}$ \\
\hline MEDIA & $0,71 \times$ & $2,02 x$ & $0,76 X Y$ & \\
\hline
\end{tabular}

C.V. $=10,5 \%$

1 - Médias de meios de cultura e médias de fungos seguidas de mesma letra não diferem estatisticamente entre si (Tukey $1 \%$ ). Os valores foram obtidos da média de 4 repetições (Placas de Petri). 
4.2.6. Avaliasão do hidrolisado de madeira-ägar como meio de cultura para fungos termófilos isolados de cava cos de eucalipto.

A elabora ţão de um meio sölido contendo hidroiisado de madeira com posterior inoculação de cinco gêneros de fungos texmófilos forneceu, como parâmetro de anälise deste meio, taxas de crescimento micelial relacionadas na Tabela 24 . Os resultados obtidos mostraram o gênero Rhizomucor com taxa média, significativamente, maior que os outros gêneros, na temperatura de $40^{\circ} \mathrm{C}$.

$$
\text { Comparando-se as taxas apresentadas com as }
$$

observados no estudo da temperatura ötima de crescimento (Ensaio 3), exce!cão feita ao P. bacizlisporum, todos os fungos demonstraram com o meio BDA, taxas de crescimento atê três vezes maio res que as registradas com hidrolisado de madeira, provocando um certo efeito inibitório do hỉrolisado de madeira com relação aos fungos isolados em BDA. 
Tabela 24 - Taxas de crescimento $(\mathrm{mm} / \mathrm{h})$ de cinco generos de fun gos termófilos cultivados em licor de madeira-ágar, incubados por 24 horas a $40^{\circ} \mathrm{C}$.

\begin{tabular}{|c|c|c|c|c|c|}
\hline \multirow{2}{*}{ FUNGOS } & \multicolumn{5}{|c|}{ Taxas de crescimento $(\mathrm{mm} / \mathrm{h})$} \\
\hline & \multicolumn{4}{|c|}{ Repeticões } & Média \\
\hline Aspergizzus & 0,62 & 0,52 & 0,56 & 0,54 & 0,56 \\
\hline Rhizomucor & 1,31 & 1,27 & 1,27 & 1,23 & $1,27 \mathrm{~A}$ \\
\hline Sporotrichum sp & 0,25 & 0,27 & 0,27 & 0,25 & $0,26 \mathrm{D}$ \\
\hline P.bacillisporum & 0,46 & 0,48 & 0,48 & 0,42 & $0,46 \mathrm{CD}$ \\
\hline T.aurantiacus & 0,75 & 0,65 & 1,02 & 1,00 & $0,86 \mathrm{~B}$ \\
\hline
\end{tabular}

C.V. $=12.3 \%$

1 - Mẻdias seguidas de letras iguais não diferem estatisticamente entre si (Tukey $1 \%$ ). Cada repetição corresponde a una placa de Petri. 


\subsection{Identifica ķão dos fungos isolados}

Os fungos termöfilos, isolados a partir de cavacos de madeira de Eucalyptus, foram identificados de acordo com as características apresentadas a seguir:

- Aspergillus sp

Colônias flocosas, em BDA, de cor verde-claro a $20^{\circ} \mathrm{C}$ escurecendo com o aumento da temperatura, apresentando-se verde-oliva a $50^{\circ} \mathrm{C}$, micêlio hialino, com conidióforos apresentando alongamento no äpice e vesículas terminais com fiälides produzindo grande quan tidade de coñidios (ONIONS et alii, 1981). Nao foi encontrada a fase perfeita do fungo.

A descriţaó cie $A$. fumigatus, isolado e identi ficado por EVANS (1971b), se aproxima das características apre sentadas pelos isolados obtidos.

Dactylomyces thermophilus Sopp. sensu Apinis

Colônias cremes, em BDA, tornando-se alaranją das a vermelho-tijolo com a idade. Forma conidial tipo Paecilo myces, com reduzido nümero de fiảlides no conidióforo. Ascocar pos tipo cleistotëcio abundantes, livres ou confluentes. Ascos evanescentes, com ascosporos, geralmente em nümero de 8 por asCO (APINIS, 1967). 
0 material isolado se assemelha à discri sajo de talhada de APINIS (1967), apesar de COONEY \& EMERSON (1964) incluirem esta espécie dentro de Thermoascus aurantiacus. Entretanto, as formas conidiais distintas e estruturas do ascocarpo, indicam que a proposişāo de APINIS (1967) estả mais próxima da realidade.

- Penicillium bacillisporum Swift

Colônias creme, em BDA, de aspecto flocoso nu ma camada muito fina. Micélio hialino, do qual se originam inu meros penicilios curtos, hialinos, eretos, septados, do tipo si mëtrico, cujas fiálides produzem conídios em cadeias longas e paralelas (STOLK \& SANSON, 1972). Ascocarpos hã foram observados em qualq̣uer das temperaturas estudadas.

- Rhizomucor sp.

Colônias cinza, em BDA, com leve tom castanho, atë $1 \mathrm{~cm}$ de altura, de aspecto cotonoso. Esporangiófcros monopo dialmente ramificados, com tendência de apresentar maior nümero de ramifica şoess e esporângios, próximo à região apical. Columelas observadas, panduriformes ou ocasionalmente esféricas. Espo ros esféricos, azigosporos, hã sendo registrada a fase perfeita e consequente: produ são de zigosporos (SCHIPPER, 1978). 
o gênero ê distinto de Mucor pela forma ção de estolões e rizóides, de Rhizopus pela produção de esporangióforos repetidamente ramificados, além da natureza termofílica que delimita este gênero.

- Sporotrichum sp.

Colônias brancas, em BDA, de aspecto cotonoso em camada fina, passando a escurecer o reverso da placa, com a idade. Micélio hialino com grande quantidade de conídios, originados diretamente do micélio, en fiālides ou esterigmas indi

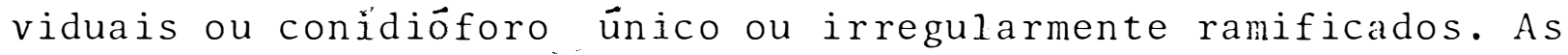
fiälides variam de muito curtas até esporos quase sêsseis (COONEY \& EMERSON, 1964). Não foi encontrada a fase perfeita.

- Thermoascus aurantiacus Miehe sensu Apinis

Colônias esbranqui çadas no início, em BDA, tor nando-se escuras quando providas de ascocarpos. Fase conidial tipo Aphanoascus. Conidiosporos, clavados ou obovados, desenvol vidos terminalmente em ramifica'sóes de hifas. Ascocarpos tipo cleistotécio, isolados ou confluentes, marron a marron-escuro, abundantes. Ascos geralmente esféricos evanescentes, com ascos poros em nümero de 8. (APINIS, 1967).

Preferiu-se a nomenclatura utilizada por APINIS (1967) por ser mais consistente, pois COONEY \& ERERSON (1964) apresentaram outra nomenclatura que abrange duas espécies pertencentes a dois gêneros diferentes. 


\section{$\vee$ - DISCUSSÃO}

5.1. Monitoramento da pilha de cavacos

o fenômeno de auto-aquecimento em pilhas de cavacos de madeira, ocorre normalmente, em fábricas de celulose e papel, sendo relacionado com a presença de madeira recêmcortada apresentando alto teor de umidade e células do alburno ainda vivas, ação de microrganismos degradadores de compostos celulares armazenados e reações de auto-oxidação originadas durante o período de estocagem (FULLER, 1985). Este aquecimento, registrado dentro do primeiro mês de monitoramento da pilha de cavacos de eucalipto, mostrou incrementes de temperatura maio res nos pontos mais internos da pilha e manutenção posterior da temperatura na faixa entre 40-60 ${ }^{\circ} \mathrm{C}$ (Tabela 4). Desse modo, são vărias possibilidades para termogênia estar relacionada a pro cessos respiratórios, haja visto que a madeira era recém-corta- 
da, com teor de umidade dos cavacos de 41\% e microrganismos ter mófilos presentes nos cavacos recém-picados (Tabela 6,10 e 11). Provavelmente, a energia liberada pela respiração forneceu condições para o desenvolvimento de microrganismos mesófilos consu midores das reservas de madeira (ASSARSSON, 1969) produzindo condições de temperatura, suficientes, para a sucessão e cresci mento dos termófilos sobre os cavacos. As flutuações de tempera tura e abaixamento do valor do pH (Tabelas 4 e 7) seriam causadas, entre outros fatores, por mudanças no nümero e tipo de microrganismos presentes na pilha (zOCH et alii, 1976).

A observação dos períodos de precipitação e seus efeitos na temperatura da pilha (Figura 3), mostrou que as camadas mais externas são sensíveis às mudanças de ambiente,com KUBLER (1982b) acrescentando o fato da pilha produzir calor porém dissipando-o, sendo totalmente perdido para o ambiente. KUBLER (1982a) ressalta, também, que se por um lado o efeito "cha mine" de ar ümido e quente em pilhas de cavacos fornecendo oxigênio aos sistemas respiratórios (células do alburno e microrga nismos), por outro lado retira calor e umidade na forma de correntes de conveção, para fora da pilha.

5.2. Isolamento de fungos termófilos

Com base nos isolamentos efetuados, com cava cos da pilha, foram obtidos seis gêneros com três espécies des- 
critas. Nota-se ser um grupo muito restrito, em comparaçao com o número de fungos isolados por BERGMAN et alii (1970) e TANSEY (3971). Quanto a frequência relativa de cada fungo, foram obser vados em maior frequência Aspergizlus e sporotrichum, porém tal como os outros fungos, sem apresentar um padrão definido de dis tribuição durante o período de estocagem. Segundo SMITH \& OFOSU ASIEDU (1972) a distribuição dos fungos na pilha é afetada pela temperatura, período de armazenamento e posição para amostragem sem efeito significativo do $\mathrm{pH}$ e teor de umidade dos cavacos. A esterilização externa dos cavacos resultou no aumento da frequência de T.aurantiacus, mostrando um provável antagonismo entre fungos termófilos descrito por JODICE et alii (1974) ou indicação da capacidade de penetração na madeira, já que houve crescimento a partir de tecidos internos, retirados dos cavacos.

Pontos próximos da fábrica e camadas superfi ciais do solo de formações florestais de eucalipto demonstraram ser possíveis fontes para contaminação e inoculação da pilha de cavacos (Tabela 15). Aspergizlus e Penicilium foram os mais fre quentes, tendo sido isolados de solo, ar e äguas residuais com D. thermophilus não isolado em nenhum destes pontos.

As observações efetuadas em solo de floresta concordam com trabalhos de WARD \& COWLEY (1972) e TANSEY \& JACK (1976), no sentido dos fungos ocorrerem no solo de floresta em concentração de propágulos normalmente baixa. O mëtodo adotado para coleta simples de esporo do ar, demonstrou somente 
a presença de termöfilos no ar (UPSHER, 1985), Aspergizlus, Rhi zomucor, P.bacizlisporum e T. aurantiacus, jā encontrados por outros autores (EVANS, 1972; HUDSON, 1973 e.. SANDHU \& SINGH, 1985). O calor presente em ăguas residuais aquecidas é suficien te para manter habitats para crescimento e propágulos de fungos termöfilos (ELLIS, 1980a), Estes propágulos foram observados na ăgua de lavagem de toras e da lagoa de efluentes e podem servir de fonte de inöculo dos termófilos, para a pilha de cavacos.

O presente trabalho de pesquisa desenvolvido, provavelmente, ë o primeiro que relaciona o fenômeno da termogê nese em pilha de cavacos de Eucalyptus ao ar livre, com a ação de fungos termöfilos, no Brasil. Estudos iniciais com cavacos de eucalipto desenvolvidos por CARVALHO et alii (1969) não cons tataram auto-aquecimento na pilha e relacionaram, apenas, fun gos de caráter mesofílico durante 7 meses de estocagem, e FOELKEL \& ZVINAKEVCIUS (1979) determinaram a influência de cavacos deteriorados, provenientes de pilha com auto-aquecimento, nas propriedades da celulose kraft sem isolar e quantificar a população de microrganismos associada a processo.

5.3. Crescimento de fungos termófilos em diferentes temperaturas.

A temperatura ótima de crescimento encontrada para os fungos estudados, em meio de BDA, (Tabelas 16 a 21) apresentou-se similar a ensaios de autores com meios de cultivo 
diferentes. CHAPMAN (1974) utilizando extrato de levedura-amidoăgar complementado com sais minerais, encontrou taxas de crescí mento para fungos mucoräceos e Sporotrichum a $40^{\circ} \mathrm{C}$, não confirmando totalmente os valores encontrados (Tabela 19). Para os ou tros fungos, foram observadas pequenas diferenças, com relação às temperaturas registradas por ROSEMBERG (1975) que concordando com CRISAN (1973) afirma serem estas diferenças devidas à especificidade do isolado e a presença de grandes quantidades de aminoâcidos e a açúcares no meio de cultura, que induziriam a repressões na sintese ou inibição de enzimas. Por outro lado, em conjunto com o substrato e quantidade de oxigênio disponível a temperatura exerce grande efeito no crescimento e tipo de esporulação de fungos termófilos, o que explicaria a ausência da fase perfeita de Rhizomucor e P.bacillisporum em meio BDA (DE PLOEY \& FERGUS, 1975 e DEPLOEY, 1985).

$\mathrm{Na}$ discussão do caräter termófilo de cresci mento, COONEY \& EMERSON (1964) postularam que fungos termófilos são aqueles microrganismos com um mínimo de temperatura requer $\underline{i}$ do para crescimento $\left(20^{\circ} \mathrm{C}\right.$ ou mais $)$ e temperaturas mäximas de $50^{\circ} \mathrm{C}$ ou acima, colocação abrangente que incluiria certos mesóf los com variação grande nos extremos de temperatura. CP.ISAN (1964) citado por EMERSON (1968) cita a termófilia como sendo característica de microrganismos com ötimos de temperatura em $40^{\circ} \mathrm{C}$ ou mais, diferenciando sensatamente, esta classe de micror ganismos. Com base nestes autores, D.thermophilus, Rhizomucor, 
Sporotrichum e T. aurantiacus seriam considerados termófilos e considerar-se-iam Aspergillus e P.bacillisporum como mesofili cos termotolerantes. Foi discutido por vărios autores, a necessidade da determinação exata do ótimo de temperatura, pois têm sido relatado, em geral, uma queda brusca no crescimento de ter mófilos em temperatura logo acima do ponto ótimo (EMERSON, 1968 \& ROSEMBERG, 1975). Este fato foi confirmado com D. thermophizus, Rhizomucor, sporotrichum, T. aurantiacus que mostraram ótimo crescimento a $50^{\circ} \mathrm{C}$, e ausência de crescimento a 60 e $70^{\circ} \mathrm{C}$.

5.4. Germinação de esporos de fungos isolados em diferentes temperaturas.

A anălise do efeito da temperatura sobre a ger minação dos esporos indicou estreito relacionamento da temperatura e o menor período latente de germinação (Tabela 22). A exceção de sporotrichum que germinou somente a $30^{\circ} \mathrm{C}$, todos os fun gos demostraram menor tempo para lançamento do tubo germinativo, em temperaturas próximas da temperatura ötima de crescimento.A $\underline{\underline{s}}$ pergilzus, P.bacillisporum e Rhizomucor possuiram capacidade de germinar a $20^{\circ} \mathrm{C}$ participando, possivelmente, dos processos iniciais de termogênese biológica, enquanto D.termophilus, Sporo trichum e T.aurantiacus participariam do processo de auto-aquecimento, no instante em que a temperatura atingisse a capacidade germinativa dos esporos (COCHRANE, 1958). 
5.5. Crescimento de fungos isolados em algumas fontes de carbono.

Diferentes fontes de carbono produziram compor tamento diferenciado na taxa de crescimento de Aspergizzus, Rhi zomucor e T.aurantiacus, quando analisadas as taxas de cresci mento (Tabela 23). O crescimento de Rhizomucor foi o melhor em todos os tratamentos, fato relacionado com a temperatura de $40^{\circ} \mathrm{C}$ adotada para o ensaio (ponto ótimo para este fungo). O ami do foi a fonte de carbono de maiores taxas de crescimento, com pequenas diferenças de dextrose, sacarose e da testemunha, e di ferenças significativas destes com hidrolisado de madeira e car boximetil celulose, mostrando efeitos negativos no desenvolvi mento dos fungos e estabelecimento de uma possível inibição ao crescimento pois os valores médios estão abaixo dos registrados com a testemunha (sem fonte de carbono).

O consumo de compostos armazenados nas cêlulas da madeira pode estar ligado às preferências nutricionais cos fungos estudados (OBERT, 1979), pois dextrose, sacarose e amido estão normalmente presentes em cēlulas vegetais (BERGMAN, 1972) e fazem parte da fração de extrativos da madeira. A composição do hidrolisado de madeira não foi determinada, mas admite-se compostos hemicelulósicos, substâncias pécticas, proteínas e lipídeos, pela ação da temperatura e pressão durante o cozimento (EIRA, 1975). A fração pectica é composta, principalmente, de plímeros de vărios açŭcares: galactose, ăcídos urônicos, ram 
nose, furanose, arabinose e piranose (ASPINALL, 1970), e as he miceluloses de xiloglucanas e outros açúcares, tais como, xilanas glocomananas, mananas e galacturonanas (ALBERSHEIM et a $i i$, 1973), componentes da madeira que segundo FLANNIGAN \& SELLARS (1972) são consumidos por algumas espécies de Aspergizzus, enquanto que Rhizomucor e T. aurantiacus apresentaram baixa ativi dade enzimica contra estes substratos. Explica-se assim, a sele ção de fungos observada quando do hidrolisado de madeira como meio para isolamento (Tabela 10) e menor taxa de crescimento, em comparação com BDA (Tabelas 16 a 21 e 24).

A ação celulotíca de fungos termöfilos, enfatí zada por HULME e HATTON (1976b) e ROSEMBERG (1978) não foi detectada, como reflexo da baixa utilização de carboximetil celulose como fonte de carbono e sendo este um composto mais simples do que a celulose bruta e postula-se que os mesmos fungos não teriam capacidade celulölittica (FERGUS, 1969 e OSO, 1978). Esta ação, tambëm, não foi confirmada por ADAMS \& DEPLOEY (1978) e FERRARI (comunicação pessoal) trabalhando com fungos termöfilos isolados de fäbricas de celulose, não sendo constatado o ataque a frações celulōsicas dos cavacos, pois houve produção normal de celulose quando a madeira foi origināria da pilba com auto-aquecimento (TESSER, comunicação pessoal). 


\section{VI - CONCLUSÕES}

Em concordância com os resultados obtidos com

o presente trabalho, pode-se tirar as seguintes conclusões:

1. - A pilha de cavacos de eucalipto apresentou auto-aquecimento, com temperaturas ultrapassando $50^{\circ} \mathrm{C}$, dentro das três primei ras semanas e mantendo-se elevadas atê o final de 5 meses de estocagem.

2 - O meio elaborado com hidrolisado de madeira foi pior que o meio BDA para isolamento e cultivo de fungos termöfilos.

3 - Os fungos isolados, a partir de cavacos retirados da pilha, foram identificados como Aspergillus sp., Dactylomyces thermo philus, Penicillium bacillisporum, Rhizomucor sp., Sporotri chum sp. e Thermoasous aurantiacus. Foi registrada a presença 
dos mesmos fungos isolados da pilha de cavacos, com exceção de D. thexmophilus, em solos de florestas de Eucalyptus, em äguas residuais para lavagem de toras e da lagoa de tratamento de efluentes.

4 - As frequências relativas de cada fungo, não mostraram um pa drão definido de ocorrência em função dos pontos amostrados, e no decorrer do período de armazenamento.

5 - Os fungos estudados são cosmopolitas, porëm em menor número quando comparados com o relato de outros países.

6 - As temperaturas ötimas de crescimento estudadas foram: $30^{\circ} \mathrm{C}$ pa ra Aspergizlus sp. e P.bacillisporum; $40^{\circ} \mathrm{C}$ para Rhizomucor sp. e $50^{\circ} \mathrm{C}$ para D.thermophilus, Sporotrichum sp., e T.aurantiacus. A 60 e $70^{\circ} \mathrm{C}$ não houve crescimento, em meio BDA, dos fungos iso lados.

7 - Dos fungos estudados, somente Aspergillus sp., P.bacillisporum e Rhizomucor sp. apresentaram germinação de esporos (conídios) a $20^{\circ} \mathrm{C}$ em ägar-água. Os pontos ótimos de germinação dos coni dios se aproximaram dos pontos ótimos de crescimento micelial.

8 - Não houve diferenças significativas entre dextrose, sacarose e amido como fontes de carbono para crescimento de Aspergiz zus sp. e T.aurantiacus, porëm foram significativamente superior ao hidrolisado de madeira e carboximetil celulose. Estes fun gos não apresentaram crescimento adequado em meio com hidrolisado de madeira e carboximetil celulose como fontes de carbono, sugerido suá incapacidade de degradar her icelulose e celulose. 


\section{VII - LITERATURA CITADA}

ADAMS, P.R. \& J.J. DEPLOEY, 1978. Enzime produced by thermophilic fungi. Mycologia. New York, 70:906-910.

AINSWORTH, G.C. \& P.K.C. AUSTWICK, 1955. A survey of animal mycoses in Britain: Mycological aspects. Transactions of the British Mycological Society. London. $38: 369-386$.

ALBERSHEIM, P.; W. BAUER; K. KEEGSTRA \& W. TALMADGE, 1973. The structure of the wall of suspension cultures sycamore cells. In: F. Loevres (ed.). Biogenesis of plant cell wall polysaccharides. London, Academic Press. p. 149-164. 
ANGELIS, D.F. \& M. SCAGLIA, 1980. "Slime". Algumas considerações sobre a sua natureza microbiológica. In: XIII Congresso Anual da ABCP - Trabalhos técnicos, São Paulo, 24 a 28 novembro de 1980 . p. 111-114.

APINIS, A.E., 1967. Dactylomyces and Thermoascus. Transactions of the British mycological society. London, 50:573-582.

ASPINALL, G.0., 1970. The carbohydrates: chemistry and biochemistry. W. Pigmon e D. Horton (ed). Vol. II B, 2a ed. London, Academic Press. p. 515-536.

ASSARSSON, A., 1969. Some reactions during chip storage and how to control them. Pulp and Paper Hagazine of Canada. Westmount, 70:74-79.

BARTHOLOMEW, W.V. \& A.G. NORMAN, 1953. Microbial thermogenesis in the decomposition of plant materials. IV. Influence of moisture content and of initial temperature. Journal of Bacteriology. Baltimore, 65:228-2.32.

BERGMAN, 0., 1972. Deterioration and protection of wood chips in outside chip storage. In: Symposium on production handling and transport of wood chips. FAO/NORAD, Hurdal, Norway 13 ang. - 8 sept. 1972. Roma, FAO. p. 267-287. 
BERGMAN, O \& T.NILSSON, 1971. Studies on outside storage of sawmill chips. Research Notes. Stockholm, R. 71, 54.p.

BERGMAN, 0, ; T. NILSSON \& P. JERKEMAN, 1970. Reduction of microbial deterioration in outside chip storage by alcali treatment. Svensk Papperstidning, Stockholm, 73: 653-666.

BJORKMAN, E. \& C.E. HAEGER, 1963. Outdoor storage of chips and damage by microorganisms. Tappi. Atlanta, 46:129-133.

BOIS, P.J.; R.A. FLICK \& W.D. GILMER, 1962. A study of outside storage of hard wood pulp chips in the southeast. Tappi. Atlanta, $\quad 45: 609-618$

BOOTH, C., 1971. Fungal culture media. In: C. Booth (ed.). Methods in microbiology. London and New York, Academic Press, Vol. IV, Cap. 2, p. 49-94.

BROCK, T.D. \& A.W. ROSE, 1969. Psychrophiles and thermophiles. In: J.R. Norris e D.W. Ribbons (ed). Methods in microbiology. London and New York, Academic Press. Vol. III B, cap. 7, p.161-8. 
CARVAlHo, P.C.T.; T.L. KRUGNER; A.P.M. GALVÃO \& A.S.R. COElHO, 1969. Estudos sobre o armazenamento de cavacos de Éucalyptus spp. ao ar livre. Congresso Fórestal.. Argentino, 1, Buenos Aires, 6-11 outubro 1969. Buenos Aires, Serviço National Forestal. p. 649-668.

CHAPMAN, E.S., 1974. Effect of temperature on growth rate of seven thermophilic fungi. Mycologia. New York, 66:542-546.

COCHRANE, V.W., 1958. Physiology of fungi. W.H. Freedman and Company, San Francisco. $183 \mathrm{p}$.

COWLING, E.B.; W.L. HARLEY \& J.WEINER, 1974. Changes in value and utility of pulpwood during harvesting, transport and storage. TAPPI. Atlanta, 57:120-123

CRISAN, E.V., 1973. Current concepts of thermophilism and the termophilic fungi. Mycologia, New York, 65: 1171-1198.

DEPLOEY, J.J., 1985. The influence of atmosfere composition and nutrients on the germination of Rhizomucor pusizzus. sporangiospores. Mycologia. New York, 77:97-102.

DEPLOEY, J.J. \& C.L. FERGUS, 1975. Growth and sporulation of thermophilic fungi and actinomycets in $\mathrm{O}_{2}-\mathrm{N}_{2}$ atmospheres. Mycologia. New York, 67:780-797. 
DOW DING, P., 1981. What is a extreme environment to a fungus? In: Fungi in Extreme Environments. Cambridge, Cambridge University Press. Bulletin of the British Mycological Society. Vol. 15. Supplement 2. 28p.

EIRA, A.F., 1975. O problema de acumulações limosas de origem microbiana em indüstrias de chapas de fibras da madeira. Piracicaba, ESALQ/USP. 80p. (Dissertação de Mestrado).

ELLIS, D.H., 1980a. Thermophilic fungi isolated from a heated aquatic habitat. Mycologia, New York, 72: 1030-1033.

ELLIS, D.H., 1980b. Thermophilous fungi isolated from some antartic and sub-antartic soils. Mycologia, New York, 72:10331036 .

EMERSON, R., 1968. Thermophiles. In: AINSWORTIH, G.C. \& A.S. SUSSMAN, Coord. The fungi - An Advanced Treatise, v. III. New York, Academic Press. p. 105-128.

ENGEL, V.L., 1985. Obtenção de cavacos de madeira. Piracicaba. ESALQ/USP. Departamento de Silvicultura, $18 \mathrm{p}$. (mimeografado).

ESLYN, W.E., 1973. Evaluation chemicals for controlling biodeterioration of stored wood chips. Forest Products Journal. Madison, $23: 21-25$. 
EVANS, H.C., 197la. Thermophilous fungi of coal spoil tips. I. Taxonomy. Transactions of the British Mycological Society. London, $57: 241-254$.

EVANS, H.C., 1971b. Thermophilous fungi coal spoil tips. II Ocurrence, distribution and temperature relationships. Transactions of the British Mycological Society. London, $57: 255-266$.

EVANS, H.C., 1972. Thermophilous fungi isolated from the air. Transactions of the British Mycological Society. London, $59: 516-519$.

EVELEIGH, D.E. \& D. BREWER, 1963. Studies on slime accumulations in pulp and paper mills. VI. Isolation of thermophilic and thermotolerant fungi from paper mills. Canadian Journal of Botany. Ottawa, 41:1377-1382.

FEIST, W.C.; G.J. HAJNY \& E.L. SPRINGER, 1973a. Effect of storing green wood chips at elevated temperatures. Tappi. Atlanta, $\quad 56: 91-95$.

FEIST, W.C.; E.L. SPRINGER \& G.J. HAJNY, 1973b. Spontaneous heating in piled wood chips - Contribution of bacteria. Tappi. Atlanta, 56:148-151. 
FERGUS, C.L., 1969. The cellulolytic activity of thermophilic fungi and actinomycetes. Mycologia. New York, 61:120-129.

FERNANDES, P.S., 1977. Qualidade da madeira e os fatores do meio. Publicação IF. São Paulo, 12:1-12.

FERRARI, M.P. \& T.L. KRUGNER. 1984. Microrganismos na tecnologia de produçãc de celulose. Informações SQCE. Piracicaba, 8,2 p.

FLANNIGAN, B., 1970. Degradation of arabinoxylan and carboxymetil cellulose by fungi isolated from barley kernels. Transactions of the British Mycological Society. London, $55: 277-288$.

FLANNIGAN, B. \& P.N. SELLARS, 1972. Activities of thermophilous fungi from barley kernels against arabinoxylan and carboxymetil cellulose. Transactions of the British Mycological Society. London, 58:338-341.

FOELKEL, C.E.B. \& C. ZVINAKEVICIUS, 1979. Estudo da influência da deterioração de cavacos de eucalipto nas propriedades da celulose kraft. o papel. São Paulo, $40: 40-48$. 
FUller, W.S., 1985. Chip pile storage - a review of praticcs to avoid detcrioration and economic losses. Tappi Journal. Atlanta, $68: 48-52$.

GATTANI, M.L., 1954. The agar plate spore germination method for testing fungicides. Phytopathology. Saint Paul, $44: 113-115$.

GOCHENALR, S.E., 1975. Distributional patterns of mesophilous and thermophilous microfungi in two bahamian soil. Mycopathologia, Chicago, 62:131-141.

HAJNY, G.J., 1966. Outside storage of pulpwood chips. A review and bibliography. Tappi. Atlanta, 49:97a-105a.

HATTON, J.V., 1970. Precise studies on the effect of outside chip storage on fiber yield: white spruce and lodgepole pine. Tappi. Atlanta, 53:627-638.

HATTON, J.V. \& K. HUNT, 1972. Effect of prolonged outside chip storage on yield and quality of kraft pulps from Picea glauca and Pinus contorta chips. Tappi. Atlanta, $55: 122-126$. 
HUDSON, H.J., 1973. Thermophilous and thermotolerant fungi in the air-spora at Cambridge. Transactions of the British Mycological Society. London, 60:596-598.

HULME, M.A. \& J.V. HATTON, 1976a. Influence of high temperatures during chip pile storage on hardwood fiber yields. Tappi. Atlanta, 59:154-155.

HULME, M.A. \& J.V. HATTON, 1976b. Increased kraft pulp fiber yields by chip treatment before outside storage: a laboratory assessment. Tappi. Atlanta, 59:108-111.

JAIN, M.K.; K.K. KAPOOR \& M.M. MISHRA, 1979. Cellulose activity, degradation of cellulose and lignin, and humus formation by thermophilic fungi. Transactions of the British Mycological Society. London, 73:85-89.

JODICE, R.; R. FERRARA; J. CERUTI SCURTI; N. FIUSSELlO; F. OBERT \& G. CANTINI CORTELEZZI, 1974. Miceti termofili. I. Contributo sull'isolamento, sul metabolismo e sulla capacità di degradazione di materiali organici. Allionia. Turin, 20:53-73.

KANE; B.E. \& J.T. MULLINS, 1973. Thermophilic fungi in a municipal waste compost system. Mycologia. New York, $65: 1087-1100$. 
KIRK, T.K. \& M. SHIMADA, 1985. Lignin biodegradation: The microorganism involved and the physiology and biochemistry of degradation by white-rot fungi. In: T. Higuchi (ed). Biosynthesis and biodegradation of wood components. San Diego, Academic Press. p. 579-605.

KUBLER, H., 1982a. Air convection in self-heating piles of wood chips. Tappi. Atlanta, 65:79-83.

KUBLER, H., 1982b. Self-heating of wood products due to residence oxygen. Wood Science. Madison, 15:97-100.

LIMA, A.F.; J.C. GERYTCH; M.C.S. JORDAO; M.L.O. D'ALMEIDA \& R. CORAIOlA, 1980. Efeito da estocagem de cavacos de Pinus ezziottii sobre a polpacão kraft e ap̣oveitamento de subprodutos. XIII Congresso Anual da ABCP - Tralalhos técnicos, São Paulo, 24 a 28 novembro de 1980. p. 249-256.

LINDGREN, R.M. \& W.E. ESLYN, 1961. Biological deterioration of pulpwood and pulp chips during storage. Tappi, Atlanta, $44: 419-429$.

NORMAN, A.G.; L.A. RICHARDS \& R.E. CARLYLE, 1941. Microbial thermogenesis in the decomposition of plant materials. II. Factors involved. Journal of Bacteriology. Baltimore, 41:699-724. 
OBERT, F., 1979. Sul metabolismo di mono-, oligo-e polissacaridi in thermoascus auramtiacus Miehe. Mllionia. Turin, 23:79-82.

OFOSU-ASIEDU, A. \& R.S. SiITH, 1973a. Some factors affecting wood degradation by thermophilic and thermotolerant fungi. Mycologia. New York, 65:87-98.

OFOSU-ASIEDU, A. \& R.S. SMITH, 1973b. Degradation of three softwoods by thermophilic and thermotolerant fungi. Mycologia. New York, 65:240-244.

ONIONS, A.H.S.; D. ALLSOPP \& H.O.W. EGGINS, 1981. Smith's introduction to industrial mycology. London, Edward Arnold Ltd. $398 \mathrm{p}$.

OSO, B.A., 1978. The production of cellulase by TaZaromyces emersonii. Mycologia. New York, 70:577-585.

ROSENBERG, S.L., 1975. Temperature and pH optima for 21 species of thermophilic and thermotolerant fungi. Canadian Journal of Microbialogy. Ottawa, 21:1535-40.

ROSENBERG, S.L., 1978. Cellulose and lignocellulose degradation by thermophilic and thermotolerant fungi. Mycologia, New York, 70:1-13. 
ROTHROCK JR, C.W.; R.S. STIITH \& R.H. LINDGRLN, 1961. The effects of outside storage on slash pine chips in the south. Tappi. Atlanta, 44:65-72.

SAMSON, R.A., 1981. Thermophilic fungi. A revision. In: Fungi in Extreme Environments. Cambridge, Cambridge University Press. Bulletin of the British Mycological Society. Vol. 15, Supplement 2. 28 p.

SANDHU, D.K. \& S. SINGH. 1985. Airborne thermophilous fungi at Amritsar, India. Transactions of the British Mycological Society. London, 84:41-45.

SCHIPPER, M.A.A., 1978. On the genera Rhizomucor and Parasitelza. Studies in Mycology. Baarn, 17:53-71.

SCHMI DT, F.L., 1969. Observations on spontaneous heating toward combustion of commercial chip piles. Tappi. Atlanta, 52:1700-1701.

SIMOES, J.W,; A.S.R. COELHO; H.A. MELlO \& H.T.Z. COUTO, 1980. Crescimento e produção de madeira de eucalipto. IPEF. Piracicaba, 20:77-97. 
SMiTH, R.S., 1975. Deterioration of pulpwood by fungi and its control. Transactions of the Technical Section. Vancouver; $1: 33-37$.

SHITH, R.S. \& A. OFOSU-ASIEDU, 1972. Distribution of thermophilic and thermotolerant fungi in a spruce-pine chip pile. Canaian Journal of Forest Research. Ottawa, $2: 16-26$.

SMITH, S.M., 1981. The physiological basis of response to extreme envirommental conditions. In: Fungi in Extreme Environments. Cambridge, Camibridge University Press. Bulletin of the British Mycological Society. Vol. 15, Supplement $2.28 \mathrm{p}$.

SOMSEN, R.A., 1962. Outside storage of southern pine chips. Tappi. Atlanta, $\quad 45: 623-628$.

STOLK, A.C. \& R.A. SAMSON, 1972. The genus Talaromyces. Studies on Talaromyces and related genera II. Studies in Mycology. Baarn, 2. 65 p.

SUSSMAN, A.S., 1974. Microrganismos: crescimento, nutrição e interação. J.L. Azevedo e N.G.R. Lotti. trad. São Paulo, EDART, $159 \mathrm{p}$. 
TANSEY, M.R., 1971. Isolation of thermophilic fungi from selfheated, industrial wood chip piles. Mycologia. New York. $63: 537-547$.

TANSEY, M.R. \& M.A. JACK, 1976. Thermophilic fungi in sunheated soils. Mycologia. New York. 68:1061-1075.

TANSEY, M.R. \& T.D. BROCK, 1978. Microbial life at high temperatures: ecological aspects. In: KUSHNER, D.J. ed. Microbial Life in Extreme Environments. London, Academic Press. p. 159-216.

TANSEY, M.R.; C.B. FLIERMANS \& C.D. KERN, 1979. Aerosol dissemination of veterinary pathog̉enic and human opportunistic thermophilic and thermotolerant fungi from thermal effluents of nuclear production reactors. Mycopathologia. Chicago, 69:91-115.

THORNQUIST, T. \& H. LUNDSTRON 1980. Factors affecting the ocurrence of fungi in fuel chips for domestic consumption. The Swvedish University of Agricultural Sciences. Department of Forest Products. Uppsala, R117, 36 p. 
UPSHER, F.J., 1985. Spore deposition on the exposed agar plate. Transactions of the British Mycological Society. London, $84: 162-4$.

WARD, J.E. \& G.J. COWLEY, 1972. Thermophilic fungi of some central south Carolina forest soils. Mycologia. New York. $64: 200-5$.

WEDBERG, S.E. \& L.F. RETTGER, 1941. Factors influencing microbial thermogenesis. I. Journal of Bacteriology, Baltimore, $41: 725-43$.

ZOCH, L.L.; E.L. SPRINGER \& G.J. HAJNY, 1976. Storage of aspen whole-tree chips under laboratory conditions. USDA Forest Service. FPL Research Paper. Madison, 288, 6 p. 